\title{
Changes in ENSO and Associated Overturning Circulations from Enhanced Greenhouse Gases by the End of the Twentieth Century
}

\author{
ZhengQing Ye AND William W. Hsieh \\ Department of Earth and Ocean Sciences, University of British Columbia, Vancouver, British Columbia, Canada
}

(Manuscript received 11 July 2006, in final form 2 April 2008)

\begin{abstract}
With data from 12 coupled models in the Fourth Assessment Report (AR4) of the Intergovernmental Panel on Climate Change (IPCC), climate under year 2000 greenhouse gas (GHG) + aerosol forcing was compared with climate under preindustrial conditions. In the tropical Pacific, the warming in the mean sea surface temperatures (SST) was found to have an El Niño-like pattern, while both the equatorial zonal overturning circulation and the meridional overturning circulation weakened under increased GHG forcing.

For the El Niño-Southern Oscillation (ENSO), the asymmetry in the SST anomalies between El Niño and La Niña was found to be enhanced under increased GHG, for both the ensemble model data and the observed data (1900-99). Enhanced asymmetry between El Niño and La Niña was also manifested in the anomalies of the zonal wind stress, the equatorial undercurrent, and the meridional overturning circulation in the increased GHG simulations. The enhanced asymmetry in the model SST anomalies was mainly caused by the greatly intensified vertical nonlinear dynamic heating (NDH) anomaly (i.e., product of the vertical velocity anomaly and the negative vertical temperature gradient anomaly) during El Niño (but not during La Niña). Under increased GHG, the enhanced positive NDH anomalies during El Niño, when time averaged over the whole record, would change the SST mean state by an El Niño-like pattern.
\end{abstract}

\section{Introduction}

The global atmospheric and tropical oceanic surface temperatures increased in the past century by $>0.5^{\circ} \mathrm{C}$ (Jones and Moberg 2003; Anthes et al. 2006). This warming is, at least in part, a result of emissions of greenhouse gases (GHGs) from human activities (Houghton et al. 2001). The climate change caused by the emissions of GHGs from human activities will also change the tropical Pacific climate state. ENSO, the strongest interannual signal in the tropical Pacific, changes its characteristics with the change in the background climatology (Fedorov and Philander 2001; An and Wang 2000; Ye and Hsieh 2006). Our primary interest here is to study how changes in GHGs from the preindustrial level to the year 2000 level would impact ENSO.

There is debate in the climate literature as to whether the low-frequency change of ENSO in the tropical Pa-

Corresponding author address: Zhengqing Ye, Jet Propulsion Laboratory, California Institute of Technology, 4800 Oak Grove Drive, Pasadena, CA 91109.

E-mail: zye@pacific.jpl.nasa.gov cific is generated within the tropics by tropical internal instability (Knutson and Manabe 1998), or uncoupled atmospheric noise (Thompson and Battisti 2001; Flügel et al. 2004), or whether it involves the interaction between the extratropics and the tropics (Gu and Philander 1997; Kleeman et al. 1999; Barnett et al. 1999). The zonal overturning circulation in the equatorial Pacific directly transports water mass and heat energy between the western warm pool and the eastern cool upwelling area, while the meridional overturning circulation conveys water mass and heat energy between the tropical and subtropical Pacific. McCreary and Lu (1994) and Liu (1994) investigated the fundamental dynamics of the meridional overturning circulation using simple layered thermocline models. They postulated that the subtropical water from the northeast subtropics reaches the equator via low-latitude western boundary currents or via an interior path directly linking the northeast subtropics to the central tropics.

There is also debate on whether the climate is changing into El Niño-like warming or La Niña-like cooling in the tropical Pacific. Cane et al. (1997) found that the observed SST had a cooling trend in the eastern tropical Pacific during 1900-91. However, Houghton et al. 
(2001) found that the trend for SST was El Niño-like in the tropical Pacific in many models. Meehl and Washington (1996) also noted an El Niño-like climate change in their coupled general circulation climate model (CGCM) with $\mathrm{CO}_{2}$ doubling. This paper will use the observed SST from 1900 to 1999, which was constructed using the most recently available International Comprehensive Ocean-Atmosphere Data Set (ICOADS) SST data and improved statistical methods that allow stable reconstruction using sparse data, including a modified historical bias correction for the 1939-41 period.

The meridional overturning circulation has been slowing down in the later decades during the period 1950-99 (McPhaden and Zhang 2002), though it rebounded during the short period 1998-2003 with respect to the period 1992-98 (Zhang and McPhaden 2006). According to McPhaden and Zhang (2004), there appeared to be a strong decadal variability superimposed on a linear weakening trend in the period 1953-2001. Using a coupled model, Merryfield and Boer (2005) found that anthropogenic forcing may have contributed to the observed slowdown of the meridional overturning circulation. The zonal Walker circulation driven by convection in the western equatorial $\mathrm{Pa}$ cific and subsidence in the east shows a weakening trend since the mid-nineteenth century due to anthropogenic forcing (Vecchi et al. 2006). Here we will investigate the slowdown in the oceanic zonal and meridional circulations using the Intergovernmental Panel on Climate Change (IPCC) Fourth Assessment Report (AR4) multimodel ensemble based on 12 CGCMs.

There is much uncertainty in how ENSO will change its characteristics (e.g., the amplitude and frequency) under increased GHG in the CGCMs. Guilyardi (2006) assessed the ENSO mean state-seasonal cycle interactions in 23 coupled ocean-atmosphere models by comparing the preindustrial control and the stabilized $2 \times$ $\mathrm{CO}_{2}$ and $4 \times \mathrm{CO}_{2}$ scenario runs. The ENSO amplitude was found to be an inverse function of both the mean trade winds and the relative strength of the seasonal cycle, but the relation was less clear for the ENSO frequency. Van Oldenborgh et al. (2005) found very little influence of global warming on ENSO from the results of 17 models. Merryfield (2006) compared the differences in ENSO amplitude, period, and pattern under preindustrial conditions and under $\mathrm{CO}_{2}$ doubling: The amplitude changes were not strongly related to the magnitude or pattern of surface warming. A narrow (wide) wind stress response was associated with ENSO amplitude decrease (increase). The models exhibited a mean fractional decrease in the ENSO period by about $5 \%$ and an increase in the amplitude of SST variations in the central tropical Pacific. On the other hand, Meehl et al. (2006) found that ENSO events decreased in magnitude in the future warmer climate $\left(2 \times \mathrm{CO}_{2}, 4 \times \mathrm{CO}_{2}\right.$, and other scenarios). Collins et al. (2005) showed that the most likely scenario is for no large amplitude change toward mean El Niño- or La Niña-like condition in the 20 models submitted to the Coupled Model Intercomparison Project (CMIP) by comparing the 80yr control simulation with fixed $\mathrm{CO}_{2}$ level and the $80-\mathrm{yr}$ simulation in which $\mathrm{CO}_{2}$ was increased from the control value at a rate of $1 \%$ per year compounded. In the present paper, the changes in ENSO under the committed $\mathrm{CO}_{2}$ level (i.e., the year $2000 \mathrm{CO}_{2}$ level) are examined.

ENSO displays considerable asymmetry between its warm phase (El Niño) and its cold phase (La Niña) (An 2004; Rodgers et al. 2004). The asymmetry is due to the nonlinearity of the ENSO system, as the nonlinear dynamic heating in the tropical Pacific ocean heat budget is essential in producing decadal changes in ENSO nonlinearity and asymmetry (Jin et al. 2003; An and Jin 2004). Changes in the asymmetry and nonlinearity of ENSO and associated overturning circulations are also addressed in our study.

The observed SST and the ensemble model data are described in section 2 and section 3, respectively. By comparing the ensemble model simulations under the preindustrial GHG conditions and under the present conditions, we identified climate change in the tropical Pacific (section 4), changes in the ENSO SST and zonal wind stress anomalies (section 5), and changes in the ENSO ocean circulation (section 6). A diagnostic analysis of the ocean surface temperature equation gave some explanation for the enhanced ENSO asymmetry (section 7).

\section{Observed SST}

The NOAA extended reconstructed SST data (Smith and Reynolds 2004) were used, with the data divided into the 1900-49 and 1950-99 periods. The climatological difference between the two periods suggests that the SST in the eastern-central tropical Pacific has increased by at least $0.3^{\circ} \mathrm{C}$ (Fig. 1). The climatological difference pattern resembles the El Niño pattern, with the maximum positive value in the eastern equatorial Pacific. In Fig. 1, the significance test was performed using the Student's $t$ test, where the equivalent sample size (i.e., degrees of freedom) was estimated from the autocorrelation function (von Storch and Zwiers 1999, p. 115).

Prior to calculating the composite maps for El Niño and La Niña episodes, a 3-month running mean was applied after the climatological seasonal cycle and lin- 

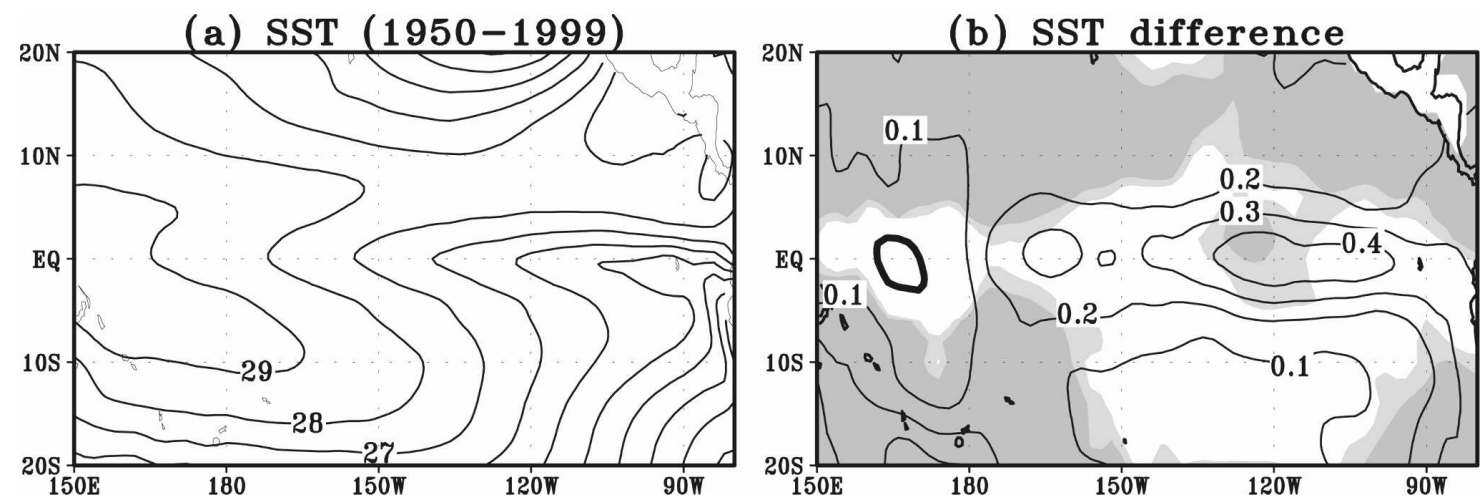

FIG. 1. (a) Observed mean SST $\left({ }^{\circ} \mathrm{C}\right)$ during 1950-99, and (b) the mean SST of 1950-99 minus that of 1900-49, with $5 \%$ and $10 \%$ significance levels based on the $t$ test, shown in dark and light gray, respectively.

ear trend were removed in each period. We examined the composite maps of SST anomalies for El Niño and La Niña episodes during each period (Fig. 2). El Niño and La Niña episodes were defined based on the Niño3.4 index (i.e., the averaged SST anomalies over the region $5^{\circ} \mathrm{S}-5^{\circ} \mathrm{N}, 120^{\circ}-170^{\circ} \mathrm{W}$ exceeding \pm 1 standard deviation). Compared to the 1900-49 period, a prominent eastward shift of positive SST anomalies appears over the eastern equatorial Pacific during El Niño in the 1950-99 period, where the maximum anomaly " $\mathrm{H}$ " has shifted from $120^{\circ} \mathrm{W}$ (Figs. 2a) to east of $90^{\circ} \mathrm{W}$ (Figs. 2c). During La Niña, a westward shift of negative SST anomalies is evident in the latter period; that is, the shift during La Niña is in opposite direction compared to that during El Niño (Figs. 2b,d). These shifts obviously enhanced the El Niño-La Niña asymmetry and
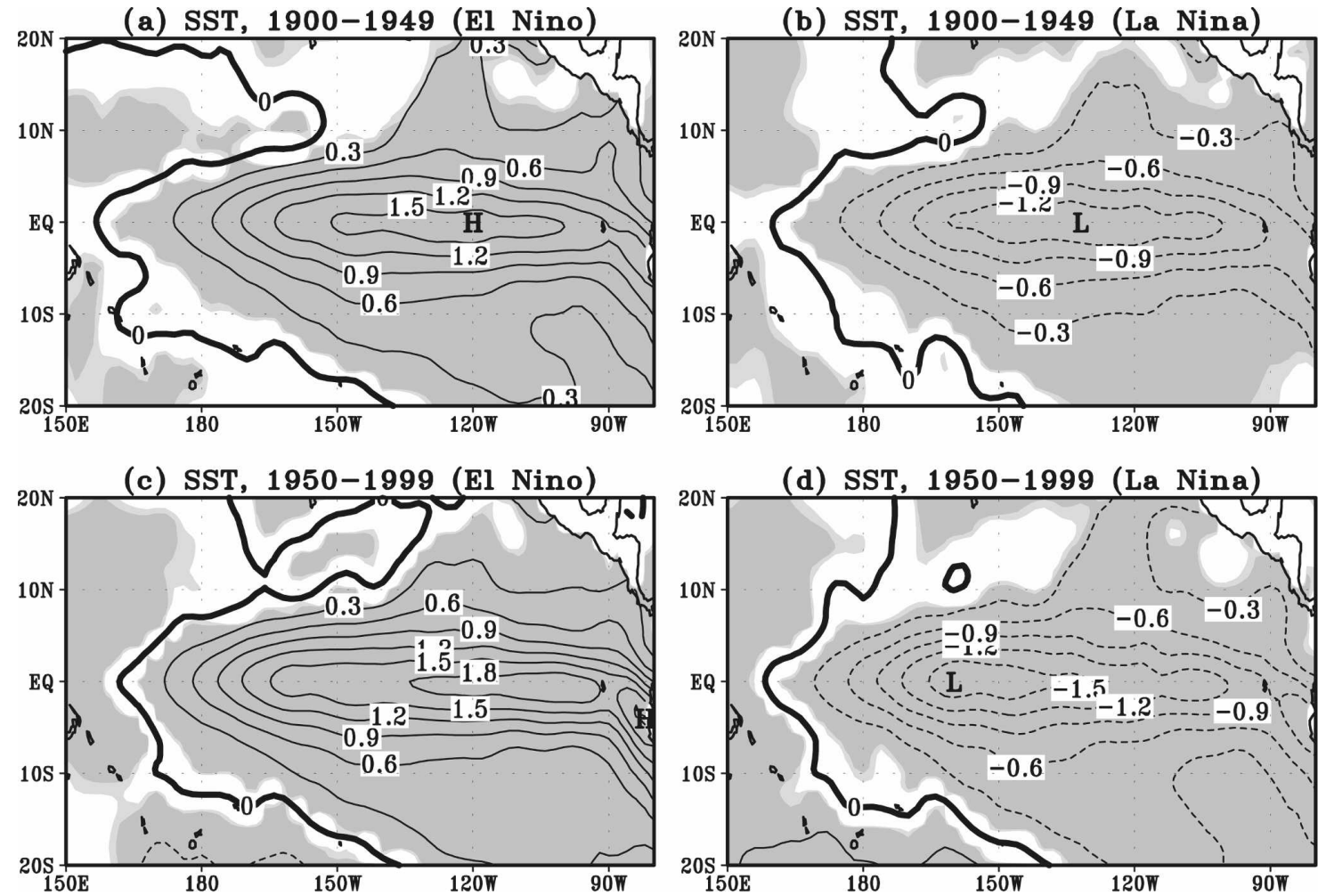

FIG. 2. Composite maps of SST anomalies $\left({ }^{\circ} \mathrm{C}\right.$ ) during (left) El Niño and (right) La Niña for (a), (b) the 1900-49 period and (c), (d) the 1950-99 period: "H" and "L" mark the location of the highest and lowest values, respectively, and 5\% and $10 \%$ significance levels based on the $t$ test are shown in gray. 
nonlinearity in the latter period. To derive an index for the asymmetry, the SST composite (Fig. 2) for El Niño and that for La Niña were added together at each grid point, then the root-mean-square (rms) deviation (averaged over the tropical Pacific) is a measure of the asymmetry, with a zero value indicating the La Niña pattern to be completely symmetrical to the El Niño pattern. The rms deviation was $0.11^{\circ} \mathrm{C}$ for the period $1900-49$ and $0.19^{\circ} \mathrm{C}$ for $1950-99$, confirming the enhanced asymmetry in the latter period. This change in the asymmetry has a longer time scale $(50 \mathrm{yr})$ compared to the decadal change in ENSO asymmetry found after the late 1970s (Ye and Hsieh 2006; Wu and Hsieh 2003; An 2004). To find a possible cause for this longer time scale change in ENSO, we will examine the effects of GHG forcing in the following sections.

\section{Model data}

Model data from the IPCC AR4 database were downloaded from the archive hosted by the Program for Climate Model Diagnosis and Intercomparison (PCMDI). The 12 CGCMs used here are the Canadian Centre for Climate Modelling and Analysis (CCCMA) CGCM3.1; Centre National de Recherches Météorologiques Coupled Global Climate Model, version 3 (CNRM-CM3); Commonwealth Scientific and Industrial Research Organisation Mark version 3.0 (CSIRO MK3.0); Geophysical Fluid Dynamics Laboratory Climate Model version 2.0 (GFDL CM2.0); Goddard Institute for Space Studies Model E-R (GISSER); Institute of Atmospheric Physics Flexible Global Ocean-Atmosphere-Land System Model gridpoint version 1.0 (IAP FGOALS-g1.0); Institute of Numerical Mathematics Coupled Model, version 3.0 (INMCM3.0); L'Institut Pierre-Simon Laplace Coupled Model, version 4 (IPSL-CM4); Model for Interdisciplinary Research on Climate 3.2, medium-resolution version [MIROC3.2(medres)]; Meteorological Institute of the University of Bonn (MIUB) ECHAM and the global Hamburg Ocean Primitive Equation (ECHO-G); Meteorological Research Institute Coupled General Circulation Model, version 2.3.2a (MRI CGCM2.3.2a); and the third climate configuration of the Met Office Unified Model (UKMO HADCM3). Documentation for the models is available on the Web site http://wwwpcmdi.llnl.gov/ipcc/model_documentation/ipcc_model_ documentation.php. We consider the preindustrial control runs (PIcntrl) and the Commit runs (Commit). PIcntrl is the preindustrial climate simulation with GHG-induced forcing fixed at the level of year 1850, whereas Commit simulates committed climate change using the forcing (GHG + aerosols) at year 2000 levels.
For each simulation run, 100 years of data were taken from each of the 12 models.

For all models, the tropical Pacific SST and zonal wind stress (WS) were analyzed. The zonal current within $2^{\circ} \mathrm{S}-2^{\circ} \mathrm{N}$ and the meridional current within $30^{\circ} \mathrm{S}-$ $30^{\circ} \mathrm{N}$ from the sea surface to $450-\mathrm{m}$ depth were also analyzed.

The meridional currents averaged over 100-300-m depth were used to detect the meridional overturning circulation in the region $30^{\circ} \mathrm{S}-30^{\circ} \mathrm{N}$ in the Pacific. The temperature and vertical velocity in the equatorial $\mathrm{Pa}-$ cific region $\left(5^{\circ} \mathrm{S}-5^{\circ} \mathrm{N}, 0-50 \mathrm{~m}\right)$ were also used in the diagnostic analysis.

For each model, the monthly mean SST, WS, ocean upper-level velocities were interpolated onto a $5^{\circ}$ longitude by $4^{\circ}$ latitude regular grid (identical to that used in the GISS-ER model) using bilinear interpolation. Anomalies were computed with respect to the mean seasonal cycle in each specific model simulation.

\section{Climate change simulated}

The climate change induced by the anthropogenic forcing was computed by subtracting the multimodel ensemble mean in the PIcntrl experiment from that in the Commit experiment. The warm pool in the western tropical Pacific and the cool tongue in the eastern tropical Pacific were both reproduced well in the mean climate in the Commit experiment (Fig. 3a), although there is a cool model bias (up to $1^{\circ} \mathrm{C}$ ) in the east-central equatorial Pacific ocean and an exaggerated westward extent of the cold tongue (cf. Fig. 1a). These biases have been recognized as common problems in most of the state-of-the-art coupled models manifesting a double intertropical convergence zone (ITCZ) (Zhang and Wang 2006; Dai 2006). The difference between the means of the two experiments shows nearly $1^{\circ} \mathrm{C}$ warming over all of tropical Pacific (Fig. 3b), with the warming pattern vaguely resembling the El Niño pattern, which has the maximum centered in the eastern-central equatorial Pacific. While each individual model revealed an El Niño-like pattern of SST change (see the figures in the appendix), there is considerable variability among the models (e.g., the maximum warming center ranged from the eastern to the western equatorial Pacific), with the standard deviation of SST change in Fig. $3 \mathrm{c}$ illustrating this intermodel variability.

The difference between the means of the two experiments also showed a positive zonal WS pattern in the western tropical Pacific (Fig. 3e), which also resembles the zonal WS anomaly pattern found during El Niño (shown later). The enhanced GHG forcing decreased the mean easterlies (Fig. 3d) along the western equa- 

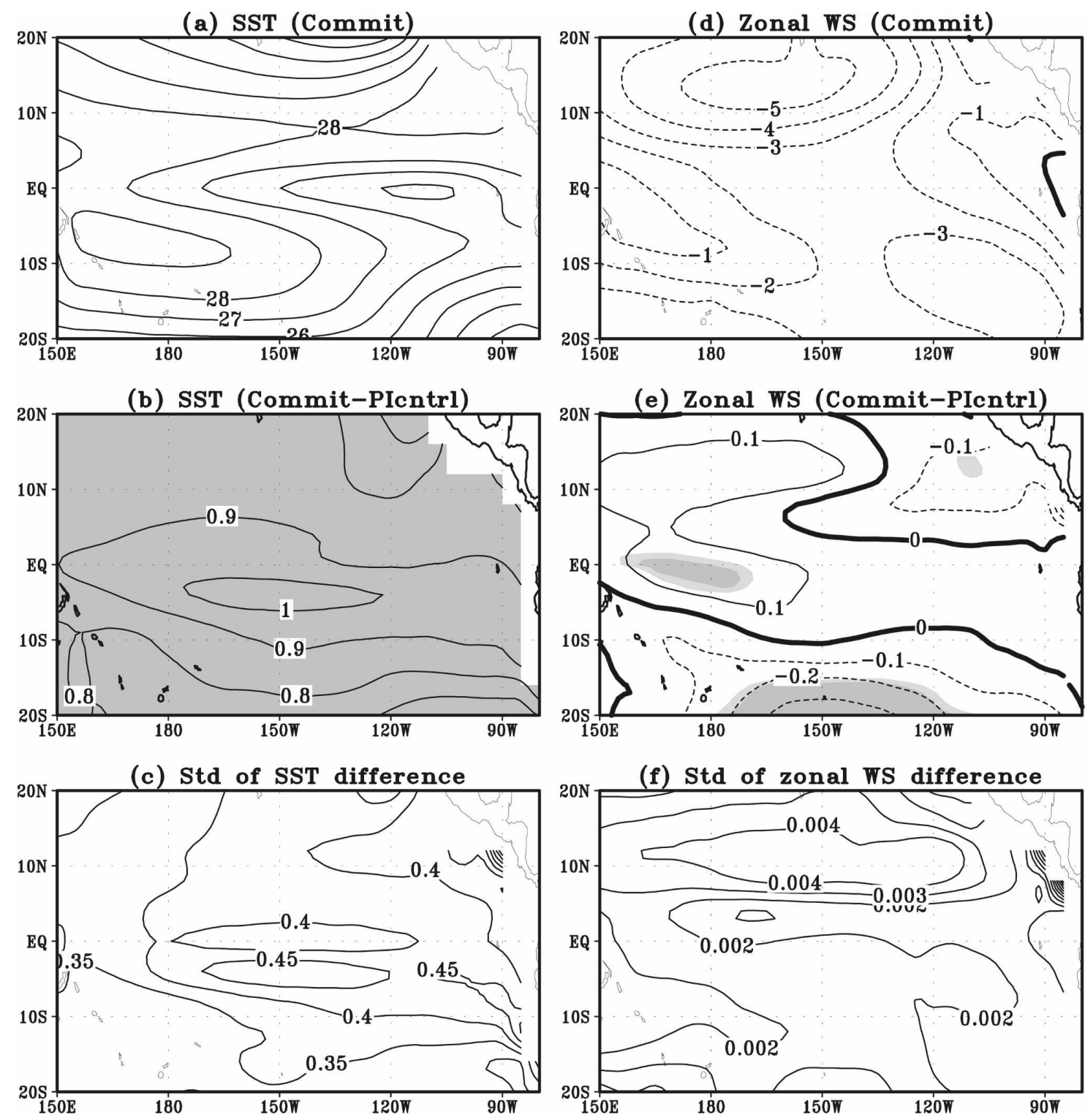

FIG. 3. Multimodel ensemble mean for the Commit runs, its change from the mean of the PIcntrl runs, and the standard deviation of this change: (a) mean SST $\left({ }^{\circ} \mathrm{C}\right)$, (b) change in the mean SST, (c) standard deviation of the SST change, (d) mean zonal WS $(0.01 \mathrm{~Pa})$, (e) change in the mean zonal WS, and (f) standard deviation of the WS change. The $5 \%$ and $10 \%$ significance levels from the $t$ test are shown in gray in (b) and (e).

torial Pacific (Fig. 3e). This agrees with the finding that the Walker circulation has been slowing down in the tropical atmosphere since the mid-nineteenth century (Vecchi et al. 2006), as the trade wind blowing across the tropical Pacific from east to west is associated with the bottom branch of the zonal Walker circulation. The mechanism for enhanced GHG forcing to weaken the Walker circulation is as follows: Using a onedimensional radiative convective model, Betts and Ridgway (1989) found that the rate of moisture increase in the boundary layer, under the assumption of constant relative humidity, outpaced the rate of increase in evaporation, thereby decreasing the convective mass circulation in the tropics. Held and Soden (2006) and Vecchi and Soden (2007) proposed that the weakening of the atmospheric overturning circulation in response to enhanced GHG forcing could be explained by the differential response of global-mean precipitation and atmospheric humidity to a warming climate. Figure $3 \mathrm{e}$ also showed a strengthening of the easterlies south of $10^{\circ} \mathrm{S}$. The intermodel variability of the zonal WS change (Fig. 3f) revealed that the models 
(a) Zonal Current (Commit)

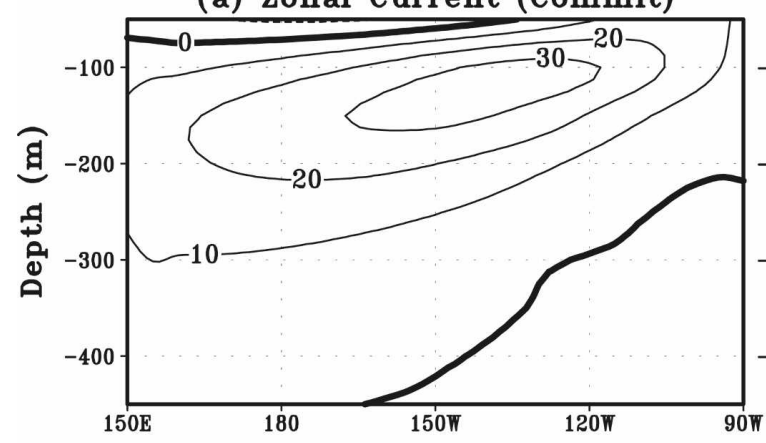

(c) Meridional current (Commit)

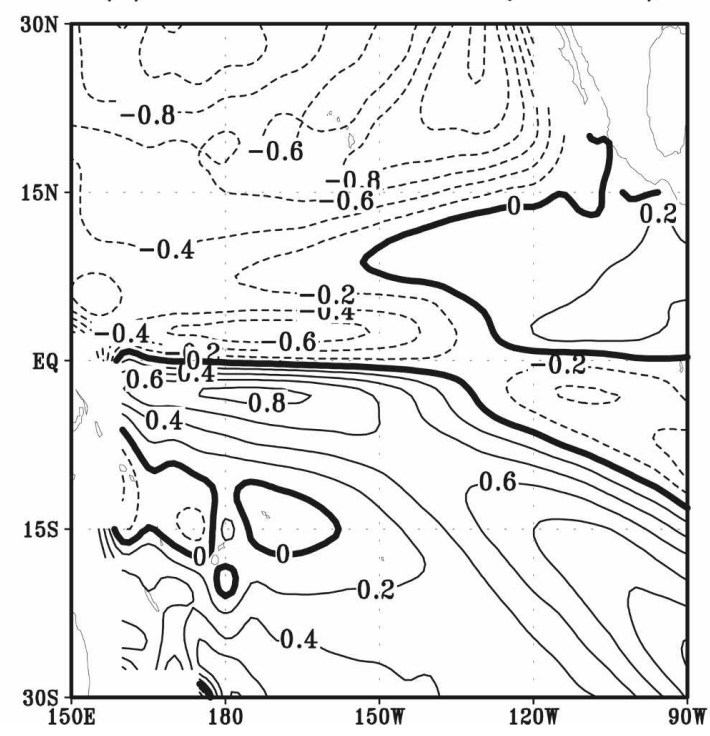

(b) Zonal Current (Commit-PIcntrl)

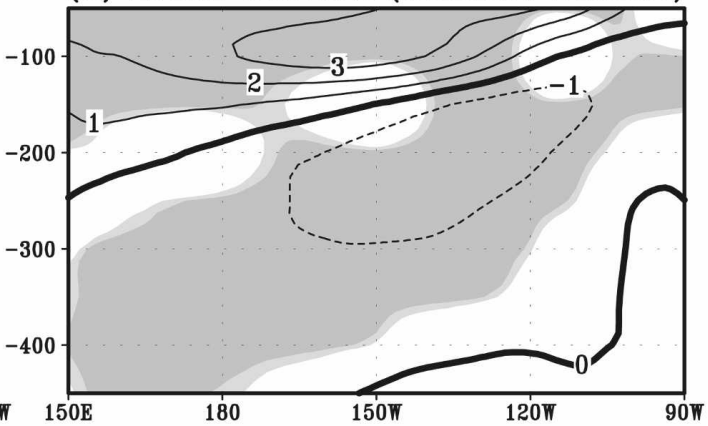

(d) Meridional current (Commit-PIcntrl)

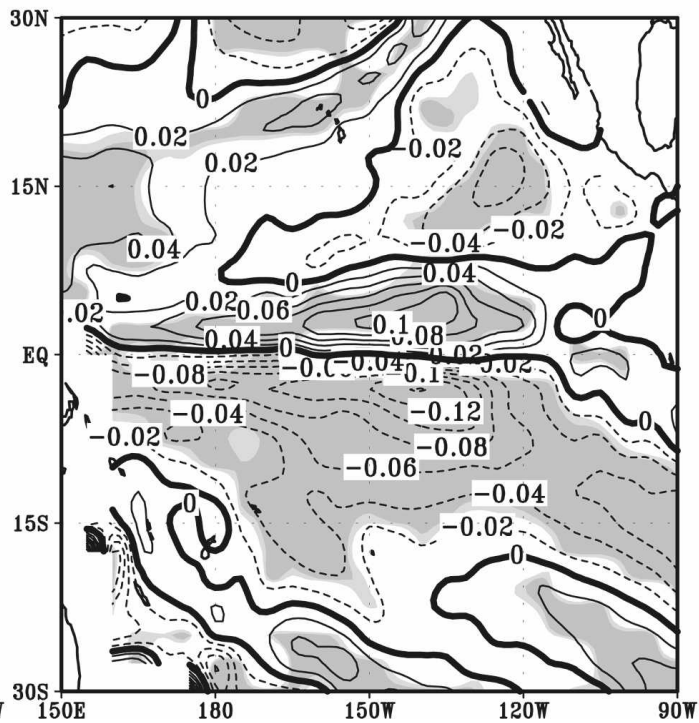

FIG. 4. Multimodel ensemble mean of velocity $\left(\mathrm{cm} \mathrm{s}^{-1}\right)$ for the Commit runs and its change from that in the PIcntrl runs: (a) the mean zonal velocity (averaged over $2^{\circ} \mathrm{S}$ and $2^{\circ} \mathrm{N}$ ), (b) the change in the mean zonal velocity, (c) the mean meridional velocity averaged over 100-300-m depth, and (d) the change in the mean meridional velocity. The 5\% and $10 \%$ significance levels from the $t$ test are shown in gray in (b) and (d).

were most consistent with each other along the equatorial belt.

In the vertical section along the equator showing the zonal current, the equatorial undercurrent along the thermocline is seen in the subsurface layer (Fig. 4a) although the simulated undercurrent is not as strong as the observed current (with a maximum of about 100 $\mathrm{cm} \mathrm{s}^{-1}$ ). The overturning equatorial circulation has weakened, as shown in the difference between the means from the Commit and PIcntrl experiments (Fig. $4 \mathrm{~b}$ ), while the undercurrent has shifted upward in the Commit runs, as Vecchi et al. (2006) have also noted an upward trend in the undercurrent position in the GFDL CM2.1 simulation data during 1861-2000. As the observed Walker circulation in the tropical atmosphere has been weakening in recent decades, Vecchi et al. felt that global warming was a likely causative factor in the weakening of the wind pattern. Here the simulated results confirm that the overturning oceanic circulation in the equatorial Pacific has also been weakening between PIcntrl and Commit.

Next, consider the meridional currents that are important for interactions between the tropics and the extratropical Pacific, as studies have shown that extratropical effects influence the tropical ENSO ( Gu and Philander 1997; Kleeman et al. 1999). Observations indicated that the cool water in the subtropical Pacific, especially in the eastern area, is subducted down and moves to the tropics by the meridional overturning circulation in the upper Pacific (McPhaden and Zhang 2004). The Pacific overturning circulation can be presented by the meridional oceanic velocity in the tropical and subtropical Pacific. The difference in the mean subsurface current (Fig. 4d) between the Commit and 
PIcntrl runs shows the Pacific meridional overturning circulation (Fig. 4c) tending to slow down, especially in the western tropical Pacific. The recent observed evidence suggests that such a slowdown of the meridional overturning circulation does exist in the upper Pacific Ocean since the 1970s (McPhaden and Zhang 2002). Although McPhaden and Zhang (2004) found that the meridional overturning circulation rebounded during 1998-2003, their latest result showed that there was a slowdown trend overlying the decadal variability in the meridional overturning circulation during 1953-2000 (Zhang and McPhaden 2006). Figures 4c,d indicate that this slowdown in the meridional overturning circulation is at least partially due to the increased GHG forcing, with the associated weakening of the Walker circulation and equatorial upwelling. Figure $4 \mathrm{~d}$ also shows that the slowdown of the overturning circulation occurs along the interior path.

The difference in the mean between the Commit runs and PIcntrl runs also shows that the GHG-induced changes are El Niño-like patterns in the tropical Pacific SST. Changes of the zonal WS, zonal overturning circulation, and meridional overturning circulation are also El Niño-like patterns (El Niño patterns are shown in the next two sections). The observed El Niño-like pattern in SST (Fig. 1b) therefore appears, at least in part, to be contributed by the GHG forcing.

\section{Changes in the ENSO SST and zonal WS}

The data from GISS-ER and IAP FGOALS-g1.0 are excluded in the analysis from now on owing to no ENSO variability in the GISS-ER model (Guilyardi 2006) and the very small seasonal cycle with the unrealistic regular interannual cycle in the IAP FGOALSg1.0 model (Guilyardi 2006; Van Oldenborgh et al. 2005). To identify El Niño and La Niña episodes in the model data, the simulated SST anomalies in the tropical Pacific $\left(20^{\circ} \mathrm{S}-20^{\circ} \mathrm{N}, 150^{\circ} \mathrm{E}-80^{\circ} \mathrm{W}\right)$ were smoothed by a 25-month running mean [as the period of the simulated ENSO was greater than $2 \mathrm{yr}$ in all 10 coupled models (Guilyardi 2006)], then the leading principal component (PC: i.e., the time series) from principal component analysis (PCA) of the smoothed SST anomalies was defined as a proxy ENSO index for each model run, with El Niño/La Niña defined based on the proxy ENSO index exceeding \pm 1 standard deviation. Composite maps of El Niño and La Niña for various variables (without the 25-month running mean smoothing) were computed for each individual model. The multimodel ensemble mean for each variable was then calculated from the individual composite maps.
ENSO is an interactive thermodynamic system between the atmosphere and ocean, where the atmosphere dynamically forces the ocean by the surface WS, while the ocean thermally drives the atmosphere by heating/cooling. Multimodel ensemble means of composite maps for SST and zonal WS anomalies over the tropical Pacific are shown in Fig. 5. A pronounced shift in the zonal location of positive SST anomalies during El Niño occurred in the Commit runs relative to the PIcntrl runs (Figs. 5a,c). The shift is in the same direction as observed (Figs. 2a,c), but there is model bias since the model SST anomalies are located farther west than the observed during El Niño, as noted by Capotondi et al. (2006). During La Niña, the shift of the negative SST anomalies is undistinguished between the Commit and PIcntrl runs (Figs. 5b,d), missing the westward shift of anomalies in the observational data (Figs. $2 \mathrm{~b}, \mathrm{~d})$. The rms index of the asymmetry between $\mathrm{El}$ Niño and La Niña was computed to be $0.045^{\circ} \mathrm{C}$ averaged for the PIcntrl runs and $0.057^{\circ} \mathrm{C}$ for the Commit runs. Although these values are considerably weaker than the observed values given in section 2, they indicate the increase of ENSO asymmetry with increased GHG. For each model, we computed the zonal location of the "center of mass" of the SST anomalies around the equator by $\Sigma\left(\mathrm{SST}_{i} L_{i}\right) / \Sigma \mathrm{SST}_{i}$, where $L_{i}$ is the longitude in degrees and $i$ is the spatial index in the domain $2^{\circ} \mathrm{S}-2^{\circ} \mathrm{N}, 150^{\circ} \mathrm{E}-80^{\circ} \mathrm{W}$. This center of mass for SST during El Niño has shifted eastward in the Commit runs relative to the PIcntrl runs by $-1^{\circ}, 25^{\circ}, 6^{\circ}, 11^{\circ},-2^{\circ}, 6^{\circ}$, $5^{\circ}, 105^{\circ}, 47^{\circ}$, and $3^{\circ}$ for the 10 models, respectively. Only 2 models (CCCMA and INM-CM) have shifted marginally westward, as the zonal grid spacing is $5^{\circ}$.

For the zonal WS during El Niño, there was eastward shift and strengthening of the westerly anomaly center along the equator (as indicated by "H") in the Commit runs relative to the PIcntrl runs (Figs. 5e,g), while during La Niña, the easterly WS anomalies along the equator showed no obvious shift (Figs. 5f,h). The contrast in the WS shift between El Niño and La Niña meant that the asymmetry and nonlinearity of ENSO were enhanced in the Commit runs. The rms index of asymmetry for the zonal WS was 0.078 (in $0.01 \mathrm{~Pa}$ ) for the PIcntrl runs and 0.100 (in $0.01 \mathrm{~Pa}$ ) for the Commit runs. The change in the asymmetry and nonlinearity of ENSO in these experiments is similar to the observed change after the late 1970 s on the decadal time scale (Ye and Hsieh 2006; Wu and Hsieh 2003; An 2004).

\section{Changes in the ENSO ocean circulation}

In the vertical section showing zonal currents along the equator, during El Niño the westward subsurface 

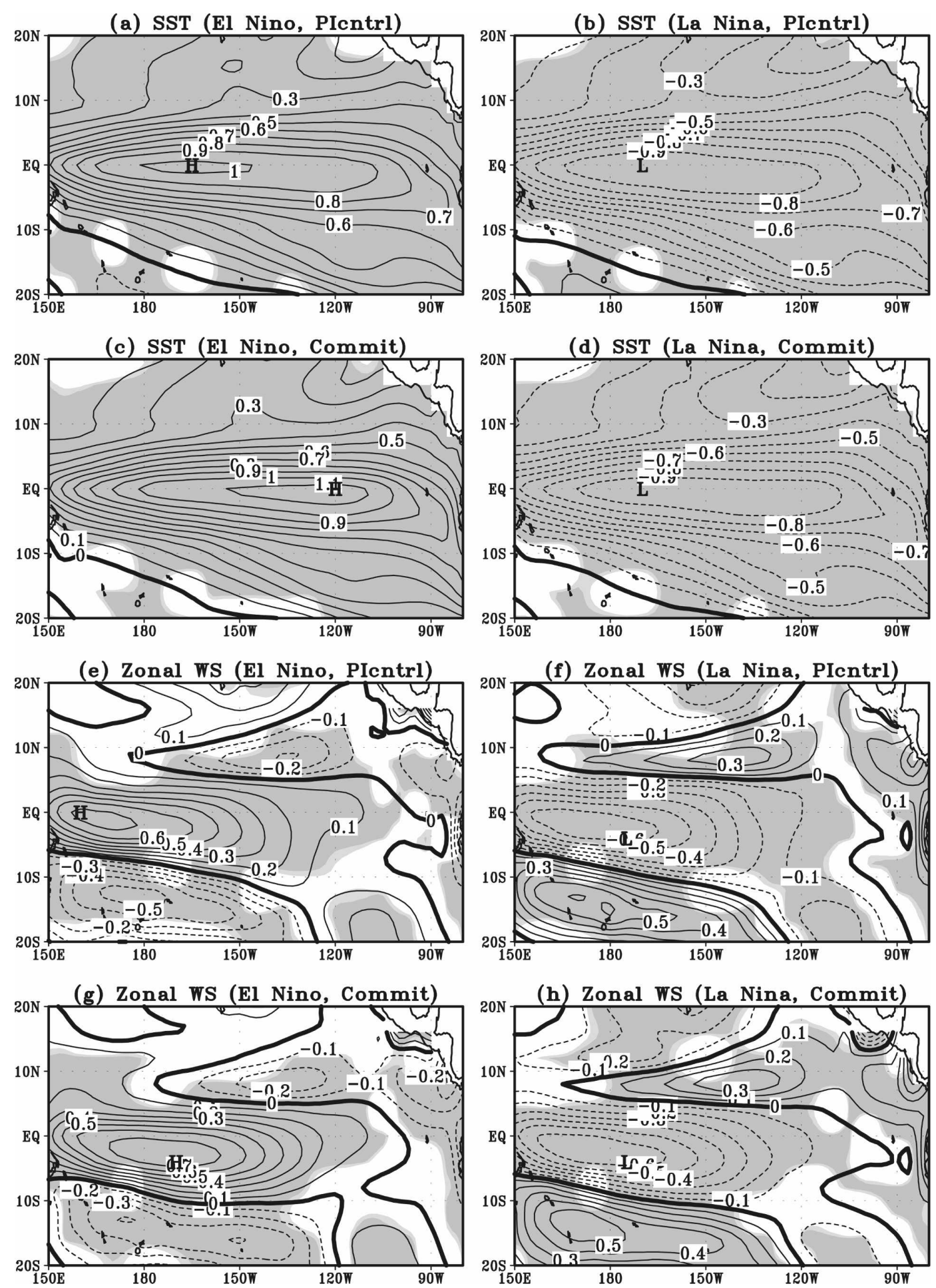

FIG. 5. Multimodel ensemble mean of SST $\left({ }^{\circ} \mathrm{C}\right)$ and zonal WS $(0.01 \mathrm{~Pa})$ composites for (left) El Niño and (right) La Niña for (a), (b), (e), (f) the PIcntrl runs; (c), (d), (g), (h) the Commit runs. "H" and "L" mark the location of the highest and lowest values, respectively, and the $5 \%$ and $10 \%$ significance levels from the $t$ test are shown in gray. 
(a) Zonal Current in PIentrl (El Nino)

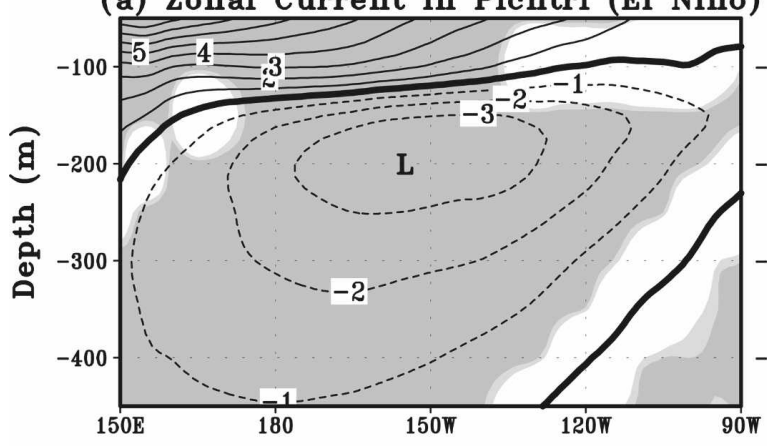

(b) Zonal Current in PIcntrl (La Nina)

(c) Zonal Current in Commit (El Nino)
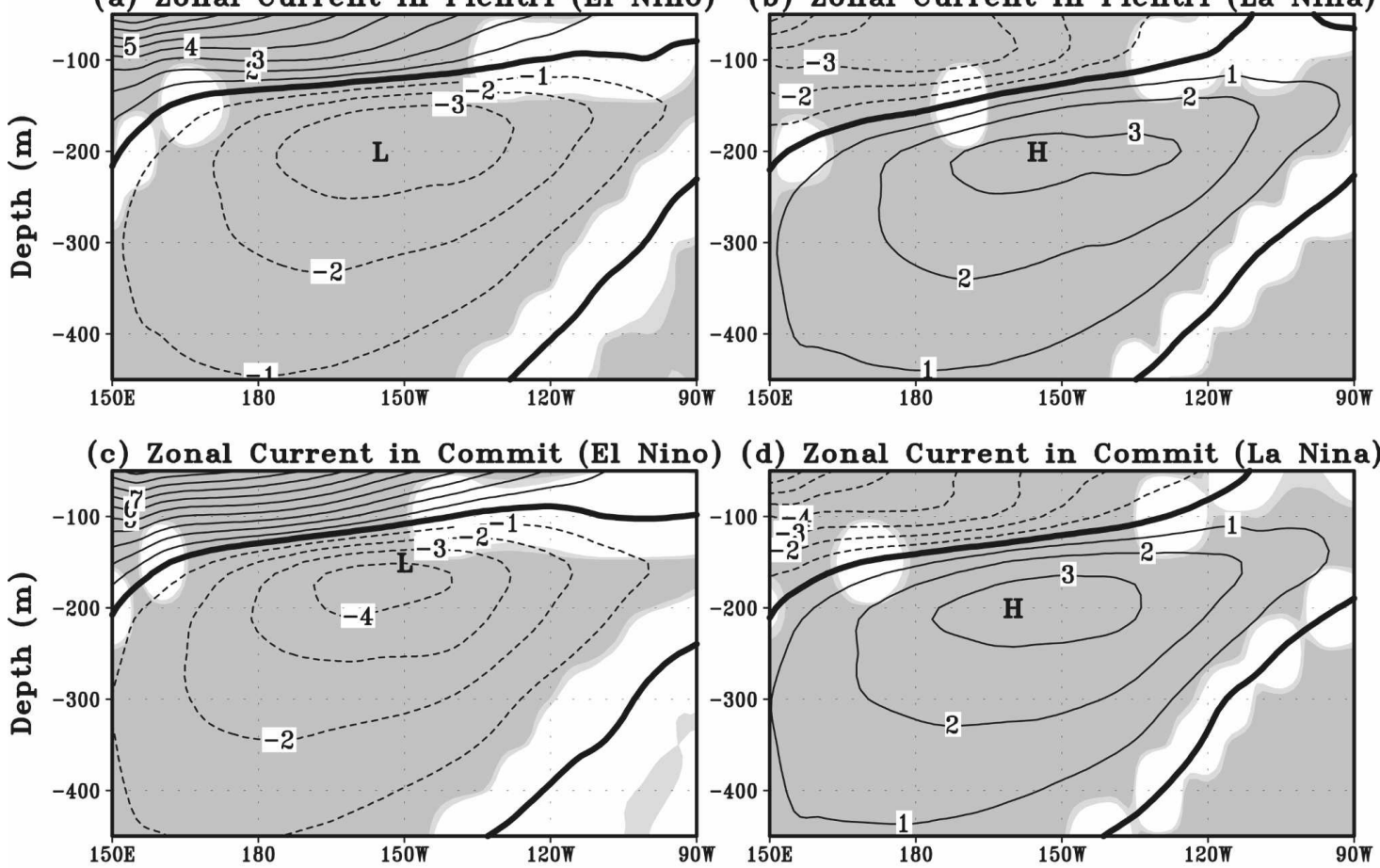

(d) Zonal Current in Commit (La Nina)

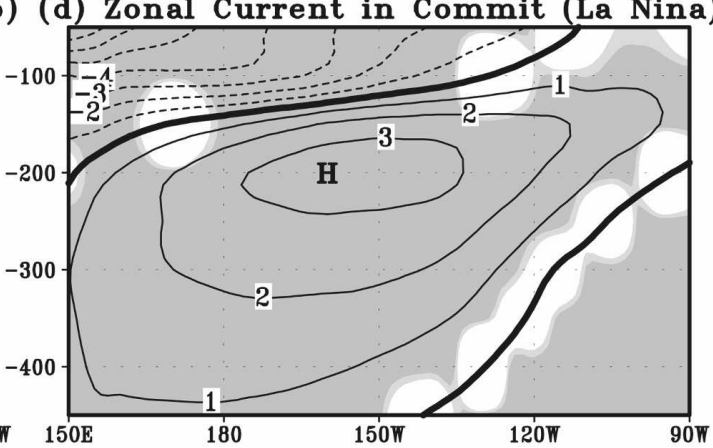

(e) Zonal Current (El Nino, CMT-PI)

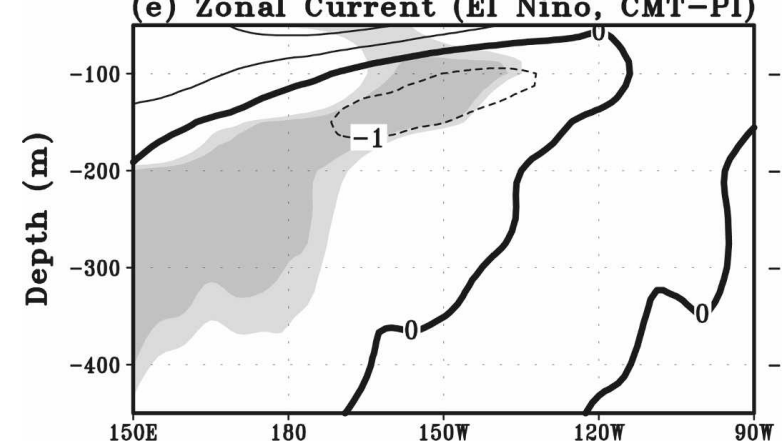

(f) Zonal Current (La Nina, CMT-PI)

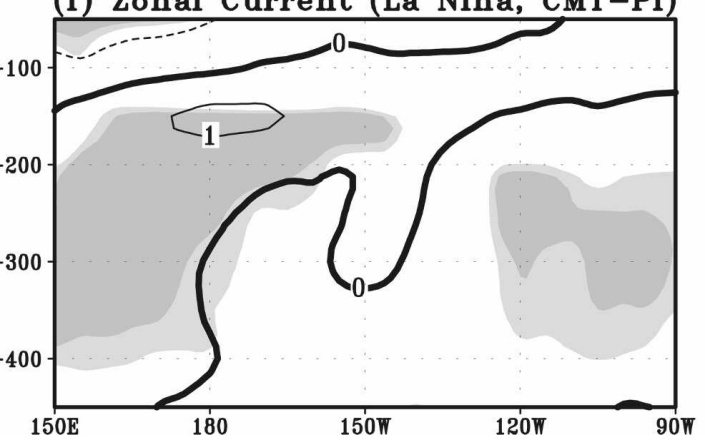

FIG. 6. Vertical section along the equator showing the multimodel ensemble mean of zonal velocity anomalies $\left(\mathrm{cm} \mathrm{s}^{-1}\right)$ averaged between $2^{\circ} \mathrm{S}$ and $2^{\circ} \mathrm{N}$ for the composite (left) El Niño and (right) La Niña for (a), (b) the PIcntrl runs and (c), (d) the Commit runs: (e) the difference between (c) and (a); (f) the difference between (d) and (b). The 5\% and 10\% significance levels from the $t$ test are shown in gray.

zonal current anomaly strengthened slightly and " $L$ " shifted eastward and upward in the Commit runs relative to the PIcntrl runs (Figs. 6a,c); in contrast, during La Niña, the eastward subsurface zonal current anomaly weakened and " $\mathrm{H}$ " shifted slightly to the west (Figs. 6,d). Thus the asymmetry in the zonal current anomalies between El Niño and La Niña strengthened in the Commit runs relative to the PIcntrl runs, as the rms index of asymmetry was $0.77 \mathrm{~cm} \mathrm{~s}^{-1}$ for the PIcntrl runs and $1.01 \mathrm{~cm} \mathrm{~s}^{-1}$ for the Commit runs.

In both El Niño and La Niña composites (Fig. 7), the subsurface meridional currents averaged between 100 and $300 \mathrm{~m}$ depth clearly showed the interior path (Mc-
Creary and Lu 1994, Liu 1994) running from the eastern subtropical Pacific Ocean to the central tropical Pacific Ocean. In the equatorial area, the location of "L" (the strongest southward current anomaly) during El Niño was found to have shifted eastward by $10^{\circ}$ in the Commit runs relative to the PIcntrl runs (Figs. 7a,c), whereas during La Niña, "H" showed no obvious shift between Figs. 7b,d. The rms index of asymmetry (computed between $5^{\circ} \mathrm{S}-5^{\circ} \mathrm{N}$ ) was $0.20 \mathrm{~cm} \mathrm{~s}^{-1}$ for the PIcntrl runs and $0.32 \mathrm{~cm} \mathrm{~s}^{-1}$ for the Commit runs. Hence the asymmetry in the subsurface meridional current anomalies between El Niño and La Niña was enhanced in the Commit runs relative to the PIcntrl runs. 

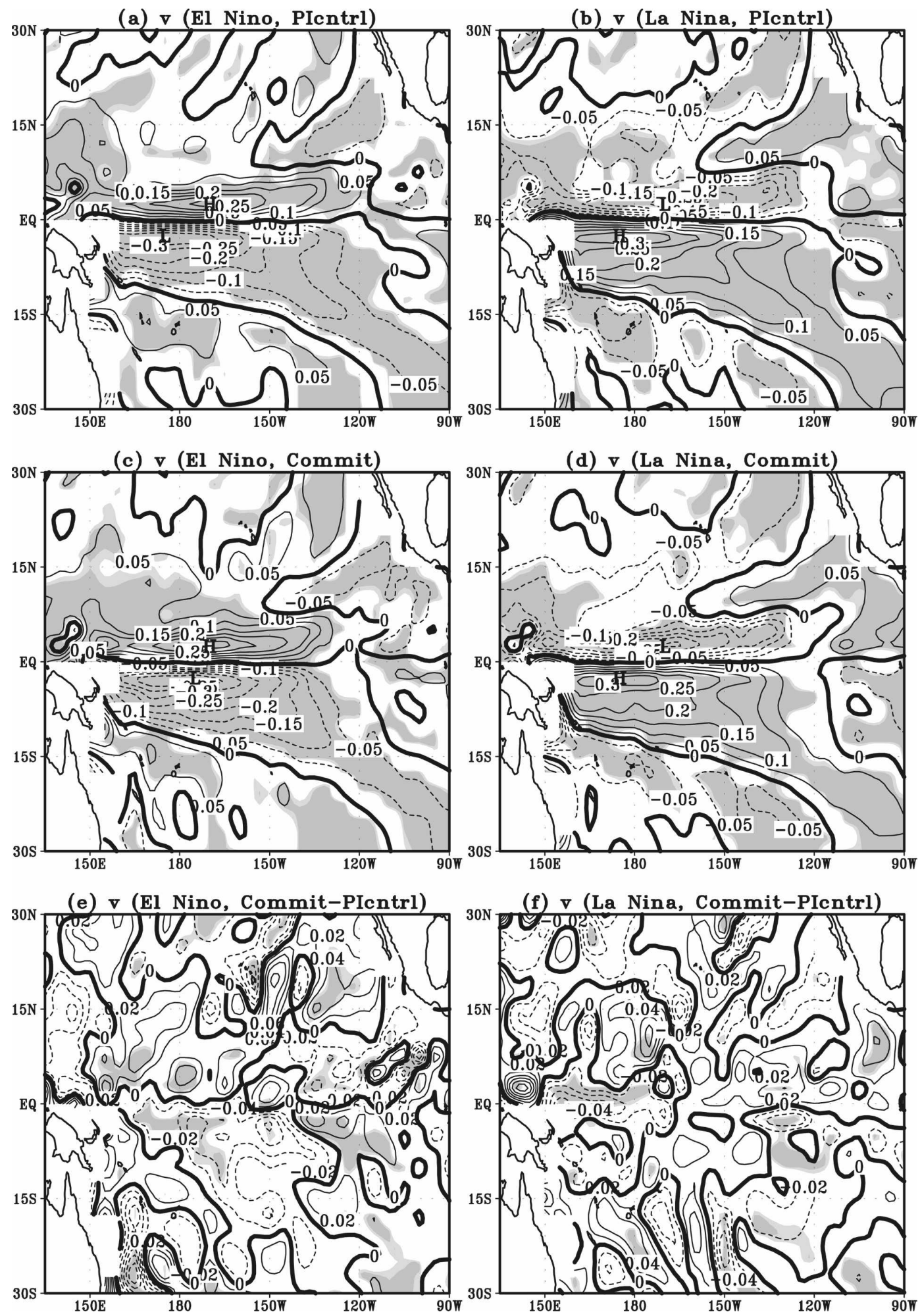

(f) $v$ (La Nina, Commit-PIcntrl)

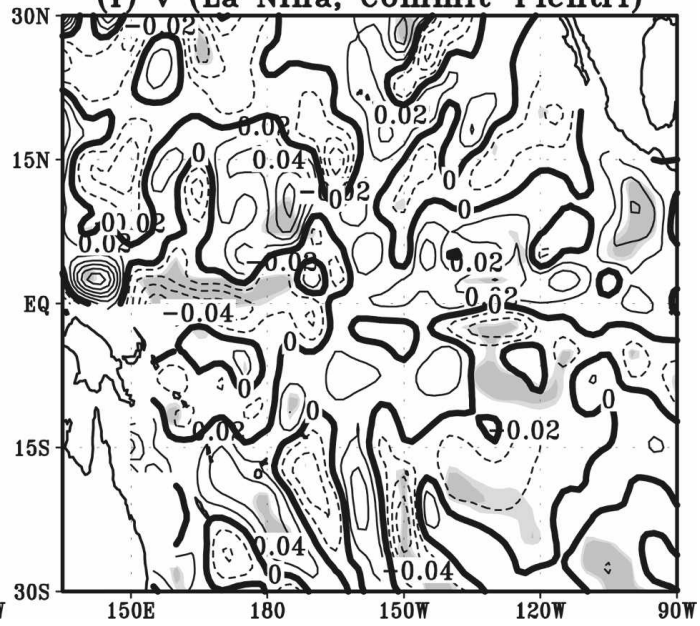

FIG. 7. Multimodel ensemble mean of subsurface meridional velocity anomalies $\left(\mathrm{cm} \mathrm{s}^{-1}\right)$ averaged over 100 300-m depth for the composite (left) El Niño and (right) La Niña: (a), (b) for the PIcntrl runs; (c), (d) for the Commit runs. (e) The difference between (c) and (a); (f) the difference between (d) and (b). The 5\% and $10 \%$ significance levels from the $t$ test are shown in gray. 
(a) $\mathrm{Tz}$ (Commit)

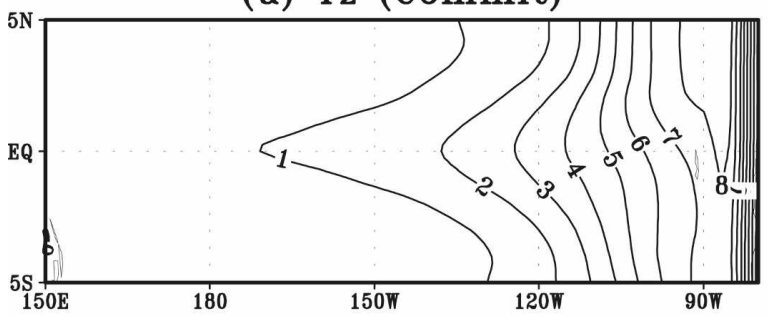

(c) $\mathbf{w}$ (Commit)

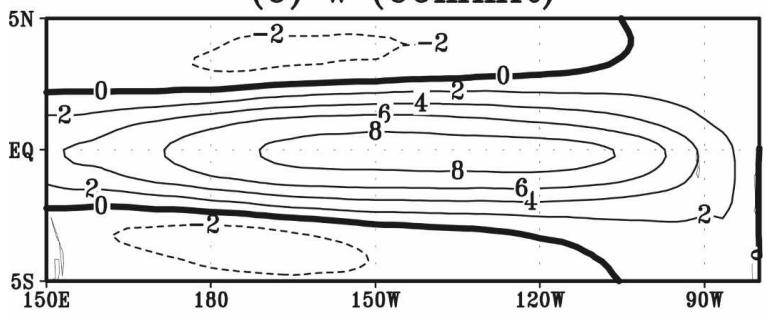

(e) Vertical NDH (Commit)

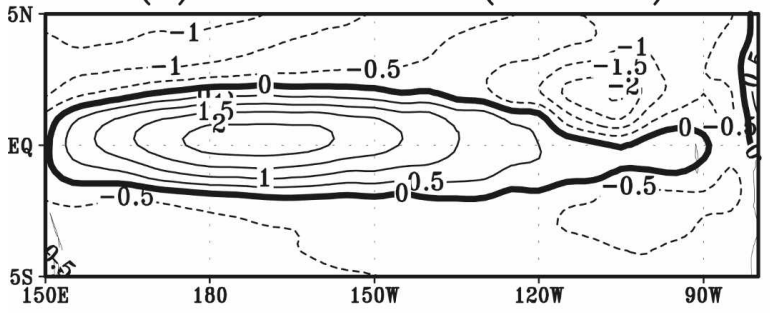

(g) $\mathrm{NDH}$ (Commit)

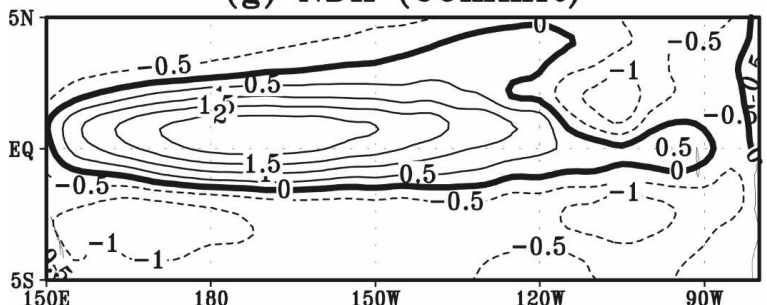

(b) Tz (Commit-PIcntrl)

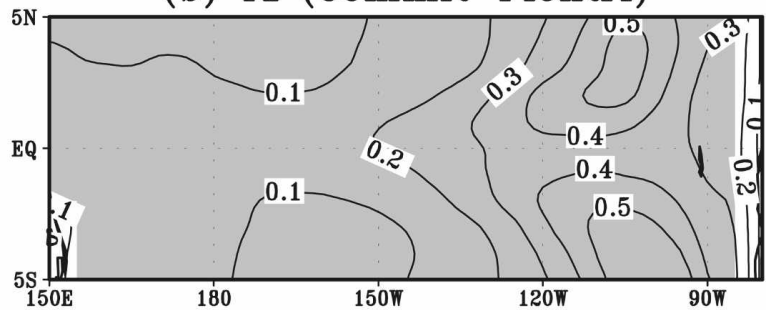

(d) $\mathrm{w}$ (Commit-PIcntrl)

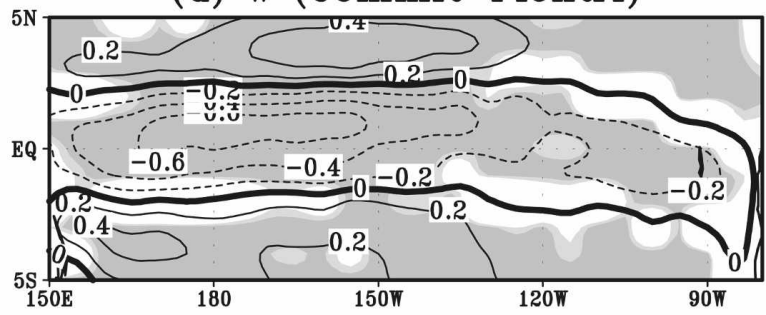

(f) Vertical NDH (Commit-PIcntrl)

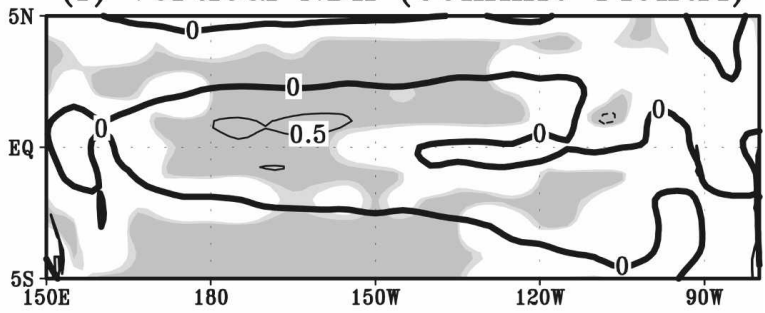

(h) NDH (Commit-PIcntrl)

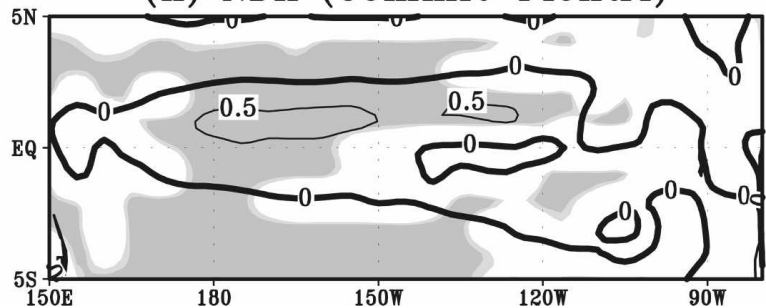

FIG. 8. Multimodel ensemble mean of (a), (b) vertical temperature gradient $\left[{ }^{\circ} \mathrm{C}(50 \mathrm{~m})^{-1}\right]$; (c), (d) vertical velocity $\left(10^{-6} \mathrm{~m} \mathrm{~s}{ }^{-1}\right)$; (e), (f) vertical nonlinear dynamic heating anomalies $\left({ }^{\circ} \mathrm{C}\right.$ month $\left.{ }^{-1}\right)$; $(\mathrm{g}),(\mathrm{h})$ and total nonlinear dynamic heating anomalies $\left({ }^{\circ} \mathrm{C}\right.$ month $\left.{ }^{-1}\right)$ for (left) the Commit runs and (right) the change from the PIcntrl runs in the ocean surface layer. The $5 \%$ and $10 \%$ significance levels from the $t$ test are shown in gray.

\section{Diagnostic analysis of the surface temperature equation}

The ocean surface temperature equation can be written as

$$
\begin{aligned}
\frac{\partial T}{\partial t}= & -\left(\bar{u} \frac{\partial T}{\partial x}+\bar{v} \frac{\partial T}{\partial y}+\bar{w} \frac{\partial T}{\partial z}+u \frac{\partial \bar{T}}{\partial x}+v \frac{\partial \bar{T}}{\partial y}+w \frac{\partial \bar{T}}{\partial z}\right) \\
& -\left(u \frac{\partial T}{\partial x}+v \frac{\partial T}{\partial y}+w \frac{\partial T}{\partial z}\right)+\text { residuals }
\end{aligned}
$$

where T, $u, v$, and $w$ are, respectively, anomalies of the SST; zonal, meridional, and vertical ocean velocities with respect to the climatological mean variables (indicated by the overbar); and "residuals" include surface heat flux anomalies, SST diffusion, subgrid-scale effects, etc. (An and Jin 2004). The first set of terms within parentheses on the right-hand side of (1) represents the linear dynamic heating (LDH) in the surface ocean, and the second set, the nonlinear dynamic heating (NDH).

The temperature equation was applied to the surface ocean layer, where the average of the SST and velocities values within $0-50-\mathrm{m}$ depth was used to represent the surface layer. The vertical temperature gradient was computed from the difference between the tem- 
(a) NDH (El Nino, PIcntrl)

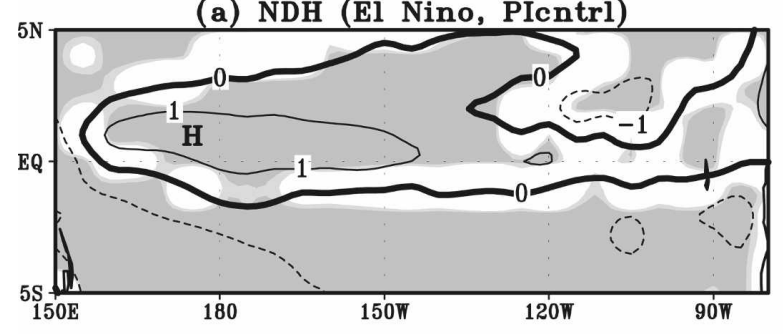

(c) NDH (El Nino, Commit)

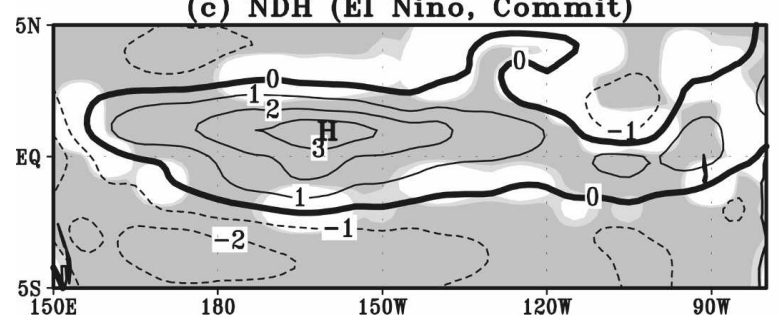

(b) NDH (La Nina, PIcntrl)

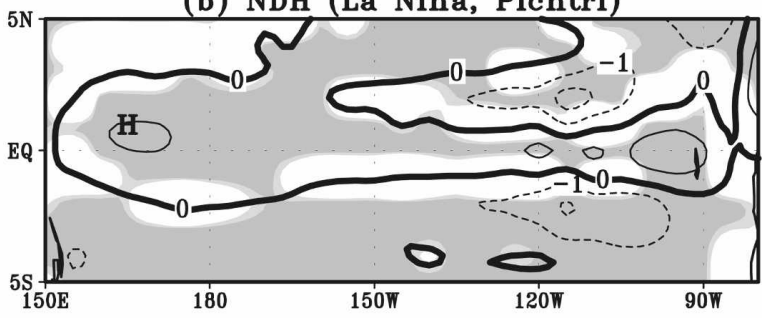

(d) NDH (La Nina, Commit)

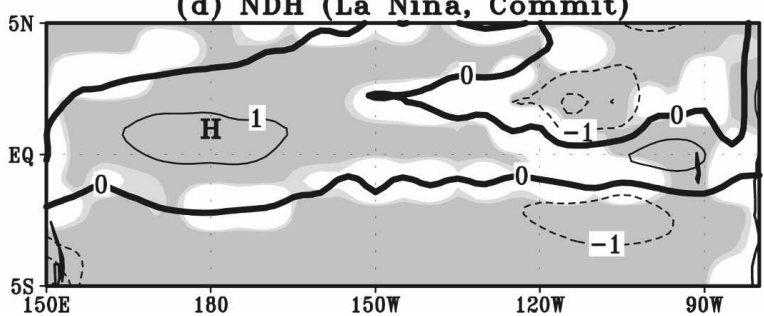

FIG. 9. Multimodel ensemble mean of surface layer nonlinear dynamic heating anomalies $\left({ }^{\circ} \mathrm{C}\right.$ month $\left.{ }^{-1}\right)$ for the composite (left) El Niño and (right) La Niña: (a), (b) for the PIcntrl runs; (c), (d) for the Commit runs. The $5 \%$ and $10 \%$ significance levels from the $t$ test are shown in gray.

perature at $0 \mathrm{~m}$ and that at $50 \mathrm{~m}$. While this is a rather crude usage of Eq. (1), a finer use of the temperature equation is difficult to perform in practice since each individual model has its own vertical resolution and mixed layer depth, with the mixed layer depth changing from the eastern to the western Pacific.

Since the vertical ocean velocities of the models MIUB ECHO-G and UKMO HadCM3 were not available, these two models were excluded in the subsequent analysis. Averaged over time (100 yr), the SST tendency contributed by the LDH terms is very small compared to the contribution from the NDH terms. Among the three NDH terms, the vertical term $-w \partial T / \partial z$ is dominant (Figs. 8e,g and 8f,h). The NDH is about $30 \%$ stronger in the Commit runs than in the PIcntrl runs (Figs. 8f or 8h). The enhanced NDH in the Commit runs does not correspond to enhanced upwelling; instead the weakened upwelling (Figs. 8c,d) is consistent with the finding in section 4 that the equatorial overturning circulation weakened in the Commit runs.

The multimodel ensemble composites during El Niño and La Niña for the NDH in the ocean surface layer are shown in Fig. 9. During both El Niño and La Niña, the $\mathrm{NDH}$ anomalies are positive along the equatorial $\mathrm{Pa}$ cific (Fig. 9). This feature of the NDH anomalies is known to cause the asymmetry between El Niño and La Niña, as the warm $\mathrm{NDH}$ anomalies enhance the warm El Niño events and weaken the cool La Niña events (An and Jin 2004). There is very substantial strengthening of the positive NDH anomaly in the equatorial belt and an eastward shift by about $25^{\circ}$ in the anomaly center (marked by " $\mathrm{H}$ ") in the Commit runs during $\mathrm{El}$
Niño (Figs. 9a,c). However, during La Niña, the changes in the NDH anomalies are relatively small between the Commit runs and PIcntrl runs (Figs. 9b,d). That the large changes in the magnitude and position of the NDH anomalies between Commit and PIcntrl runs only occurred during El Niño reflects the nonlinear nature of the change in the NDH under enhanced GHG. With the increase of NDH during El Niño in the Commit runs, one would expect an overall increase in the ENSO amplitude. However, no clear increase in the overall ENSO amplitude was found between the Commit and PIcntrl runs (see appendix). Hence other terms (e.g., the residuals and the LDH) in Eq.(1) must, over a broad area, essentially cancel the increase in the $\mathrm{NDH}$.

The NDH anomalies are mainly caused by the vertical NDH anomalies $(-w \partial T / \partial z)$, as can be seen from the similarity between the total NDH anomaly (Figs. 9c,d) and the vertical NDH anomaly (Figs. 10a,c) during El Niño and La Niña. The substantial change in the vertical NDH anomalies during El Niño in the Commit runs relative to the PIcntrl runs is caused by the increased vertical temperature gradient anomalies and the eastward shift of downwelling anomalies in the central equatorial Pacific (Figs. 10b,f,i,j). However, during La Niña, the change in the vertical NDH anomalies is relatively minor (Figs. 10c,d).

\section{Conclusions}

The El Niño-like warming in the tropical Pacific seen in the observed SST record (1900-99) was confirmed by 
(a) Vertical NDH (El Nino, Commit)

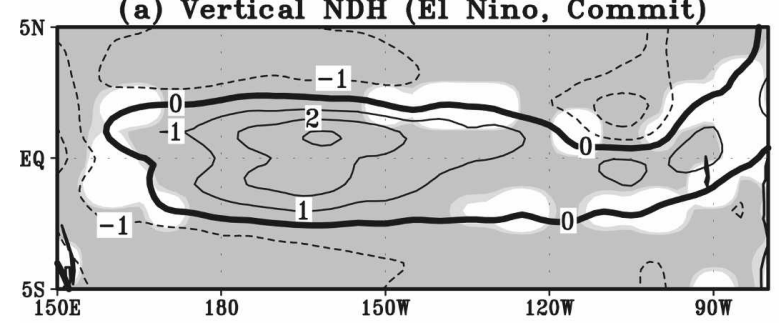

(c) Vertical NDH (La Nina, Commit)

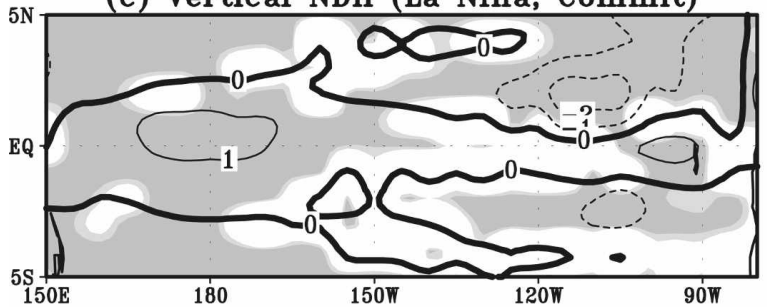

(e) $\mathrm{Tz}$ (El Nino, Commit)

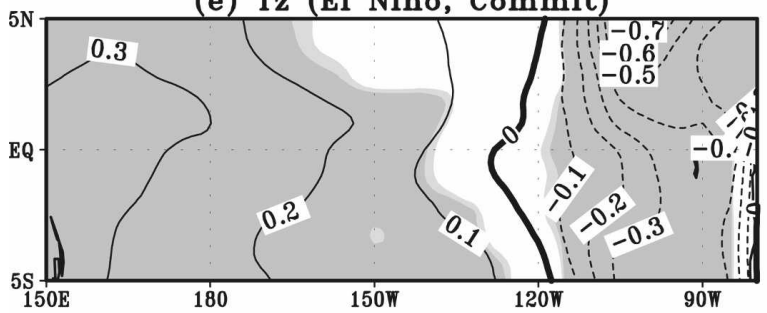

(g) Tz (La Nina, Commit)

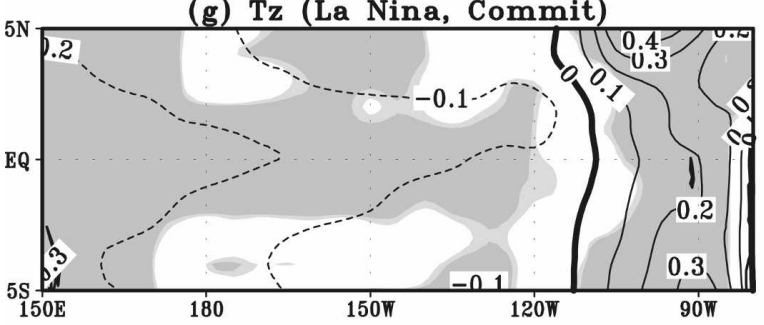

(i) $w^{*} 1$ e6 (El Nino, Commit)

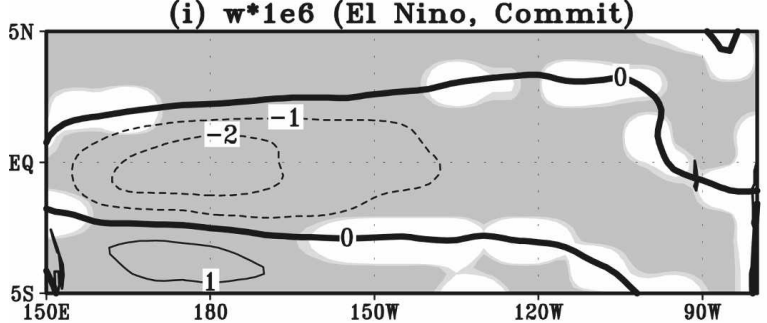

(k) $w^{*} 1 \mathrm{e} 6$ (La Nina, Commit)

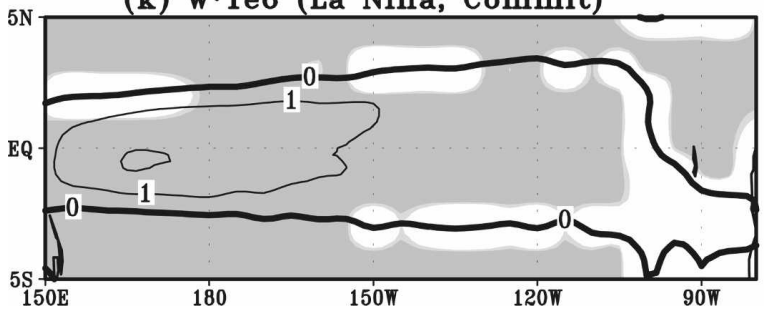

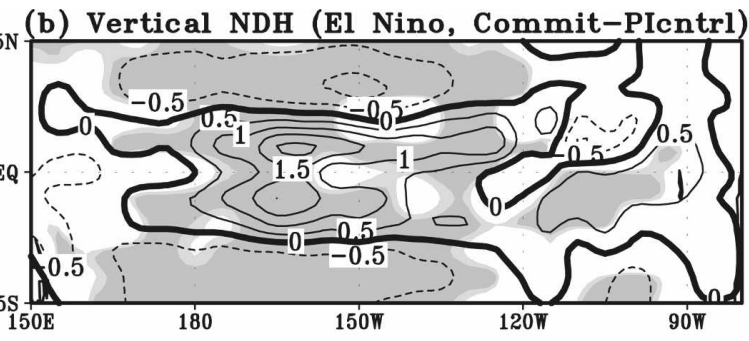

(d) Vertical NDH (La Nina, Commit-PIcntrl)

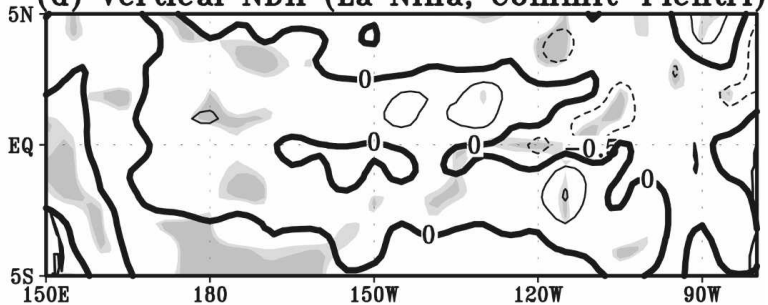

(f) $\mathrm{Tz}$ (El Nino, Commit-PIcntrl)

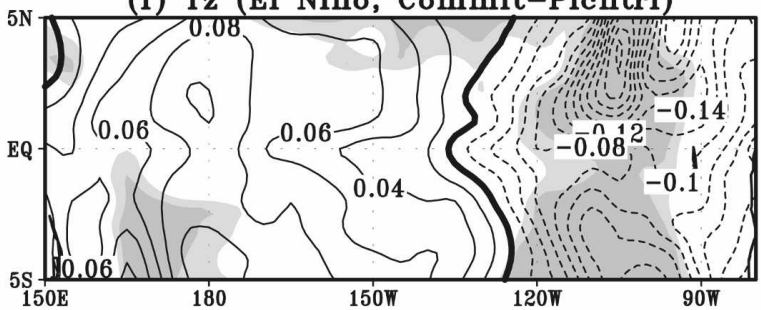

(h) Tz (La Nina, Commit-PIcntrl)

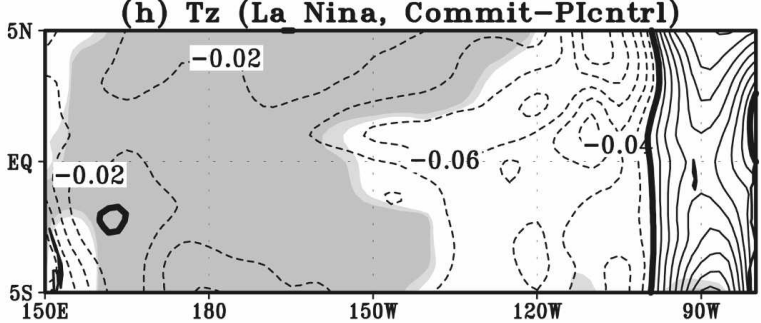

(j) $\mathrm{w}^{*}$ 1e6 (El Nino, Commit-PIcntrl)

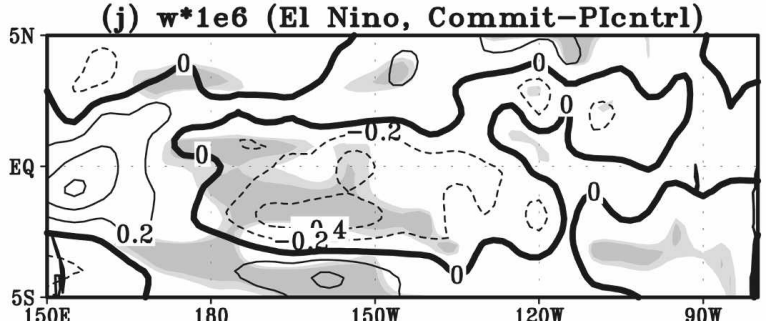

(1) w*1e6 (La Nina, Commit-PIcntrl)

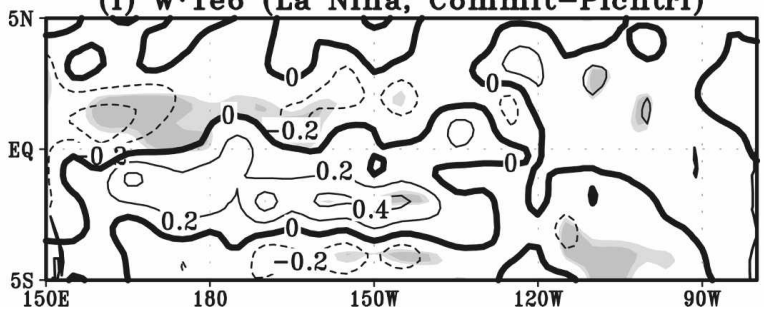

FIG. 10. Multimodel ensemble mean of the (a)-(d) surface vertical nonlinear dynamic heating $\left({ }^{\circ} \mathrm{C}\right.$ month $\left.{ }^{-1}\right),(\mathrm{e})-(\mathrm{h})$ vertical temperature gradient anomalies [ ${ }^{\circ} \mathrm{C}(50 \mathrm{~m})^{-1}$ ], and (i)-(1) vertical velocity anomalies $\left(10^{-6} \mathrm{~m} \mathrm{~s}^{-1}\right)$ during El Niño and La Niña for (left) the Commit runs and (right) the difference between the Commit and PIcntrl runs. The $5 \%$ and $10 \%$ significance levels from the $t$ test are shown in gray. 

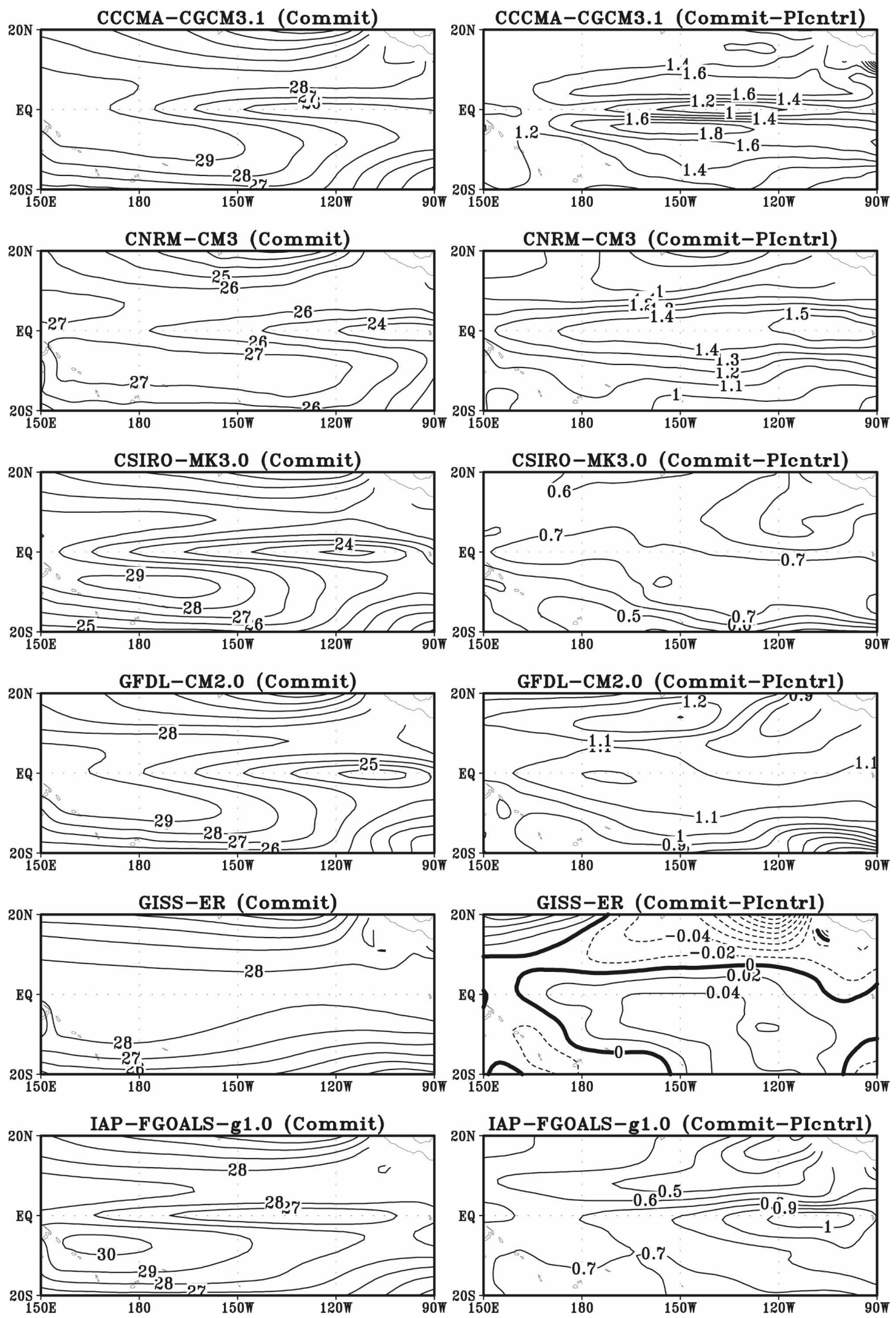

FIG. A1. SST mean $\left({ }^{\circ} \mathrm{C}\right)$ for (left) the Commit runs and (right) its difference from the mean in the Picntrl runs for 12 individual models. 

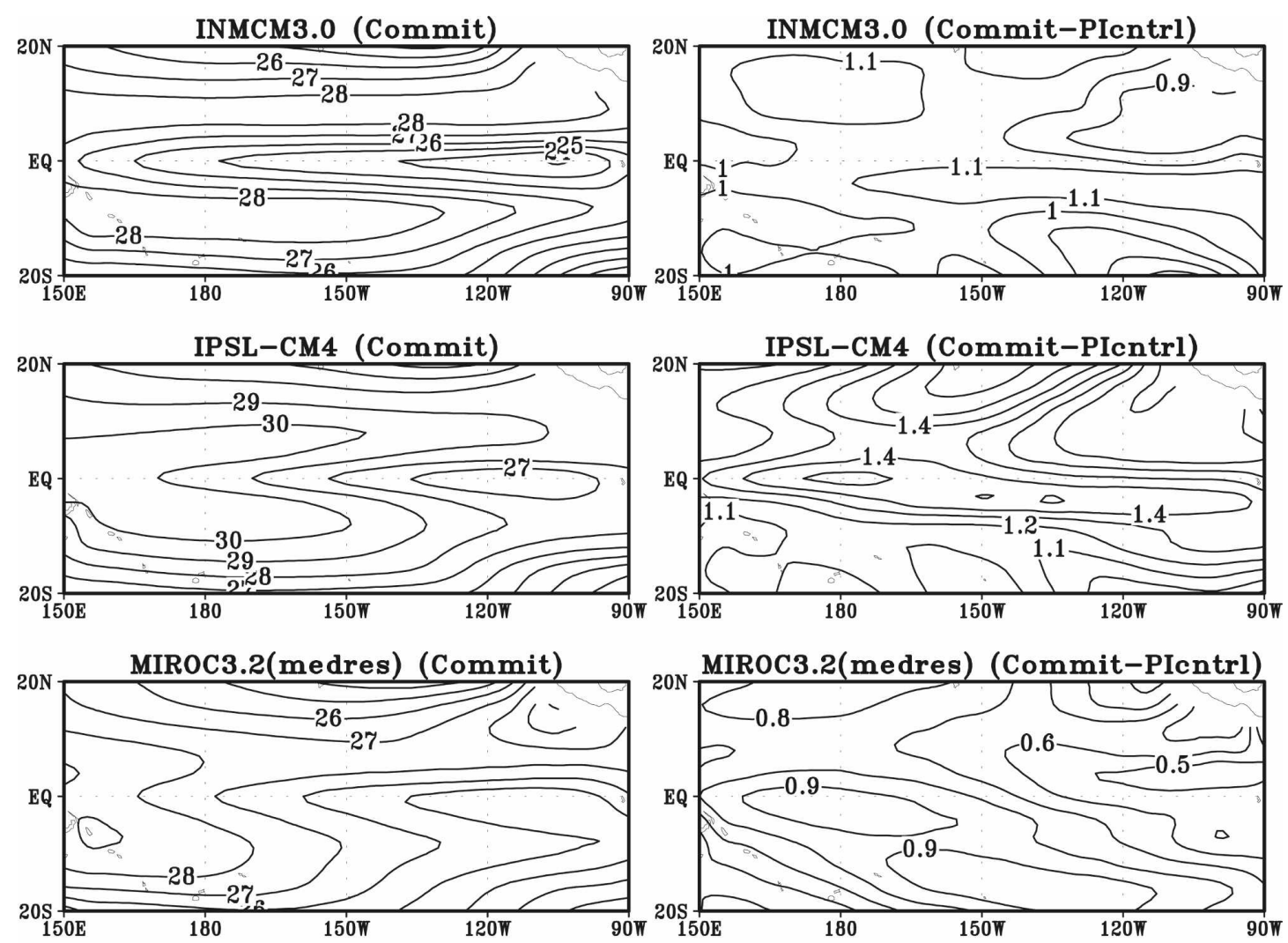

MIROC3.2(medres) (Commit-PIcntrl)
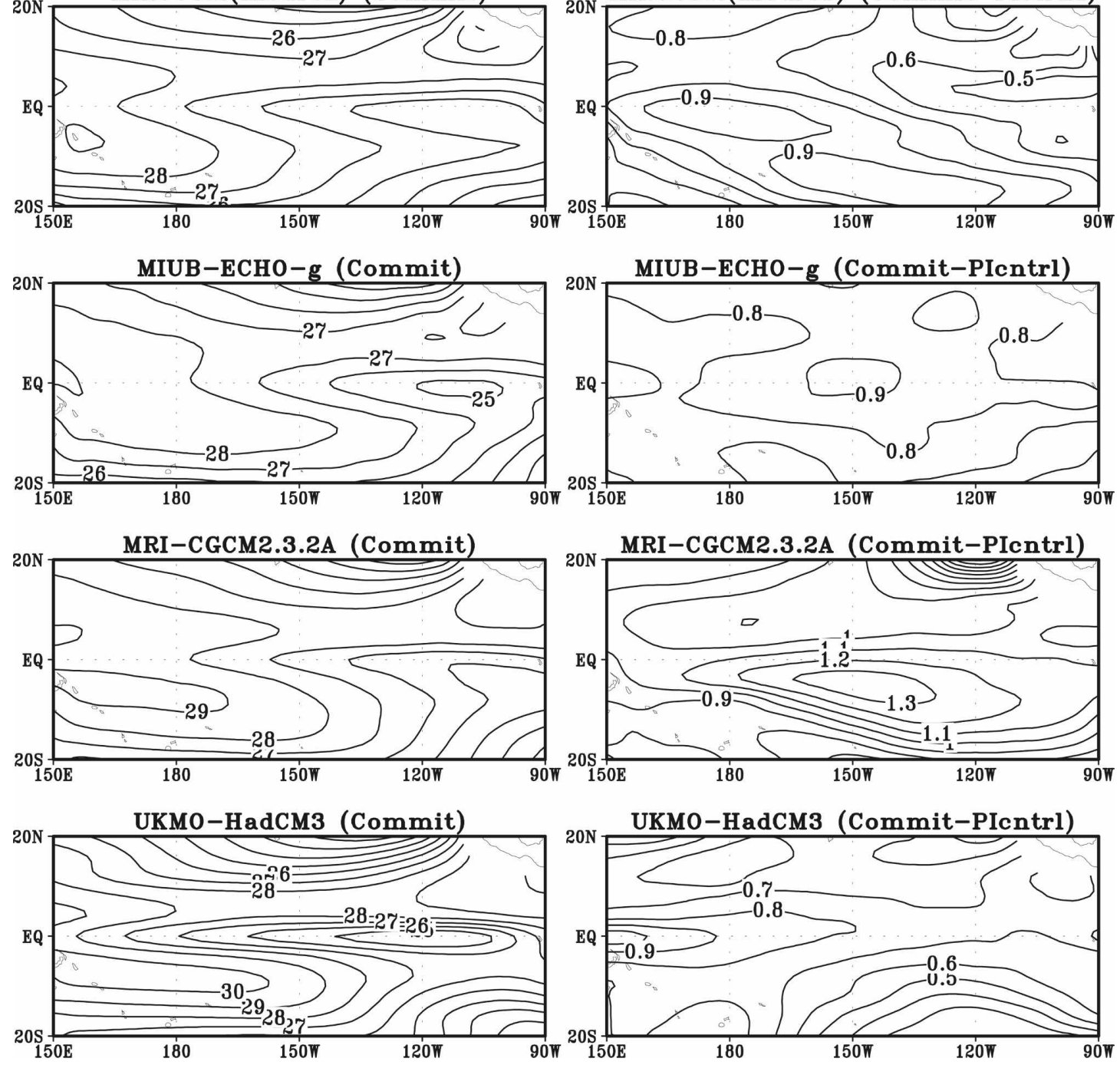

FIG. A1. (Continued) 

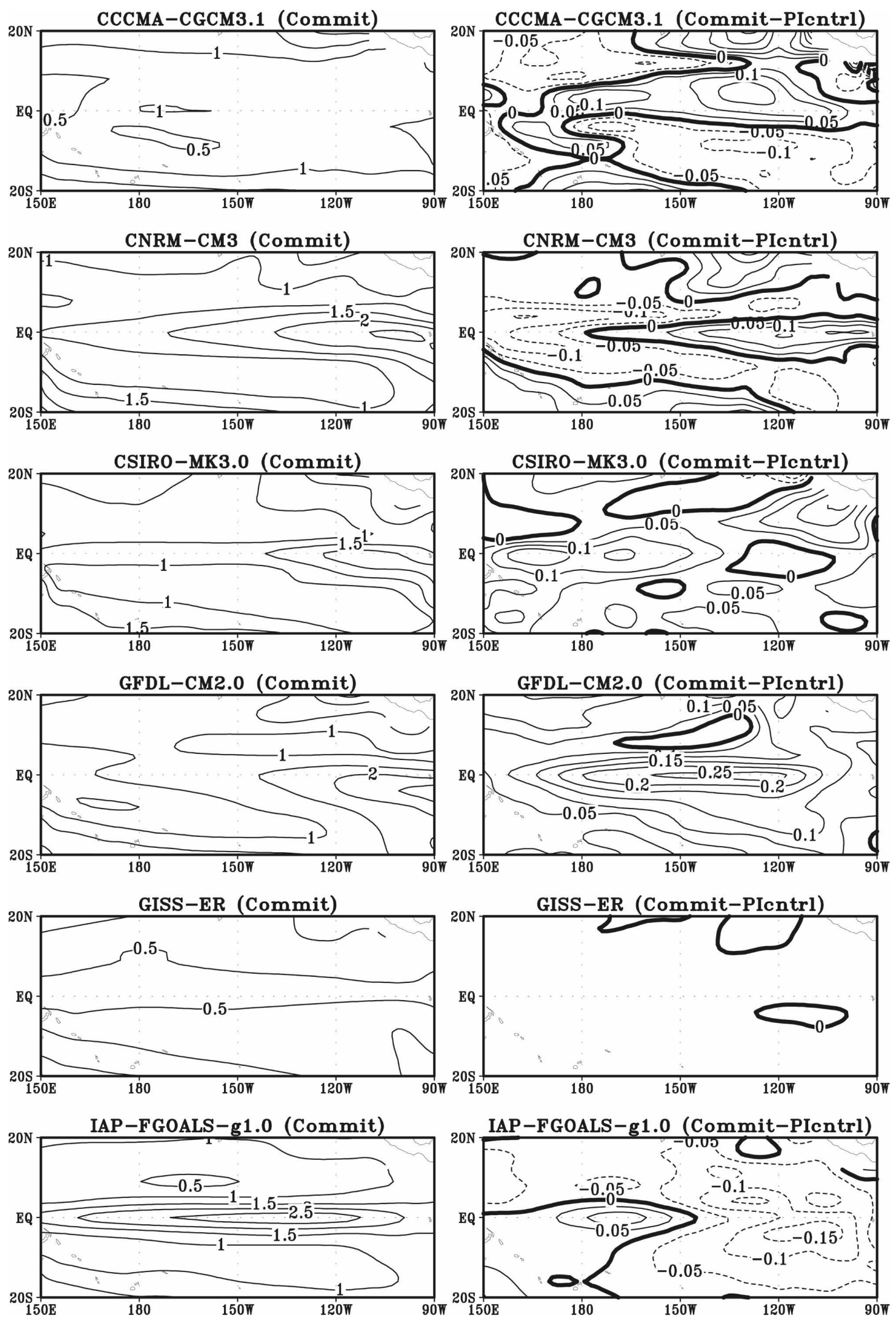

FIG. A2. SST standard deviation $\left({ }^{\circ} \mathrm{C}\right.$ ) for (left) the Commit runs (contour interval $0.5^{\circ} \mathrm{C}$ ) and (right) its difference from the standard deviation in the PIcntrl runs (contour interval $0.05^{\circ} \mathrm{C}$ ) for 12 individual models. 

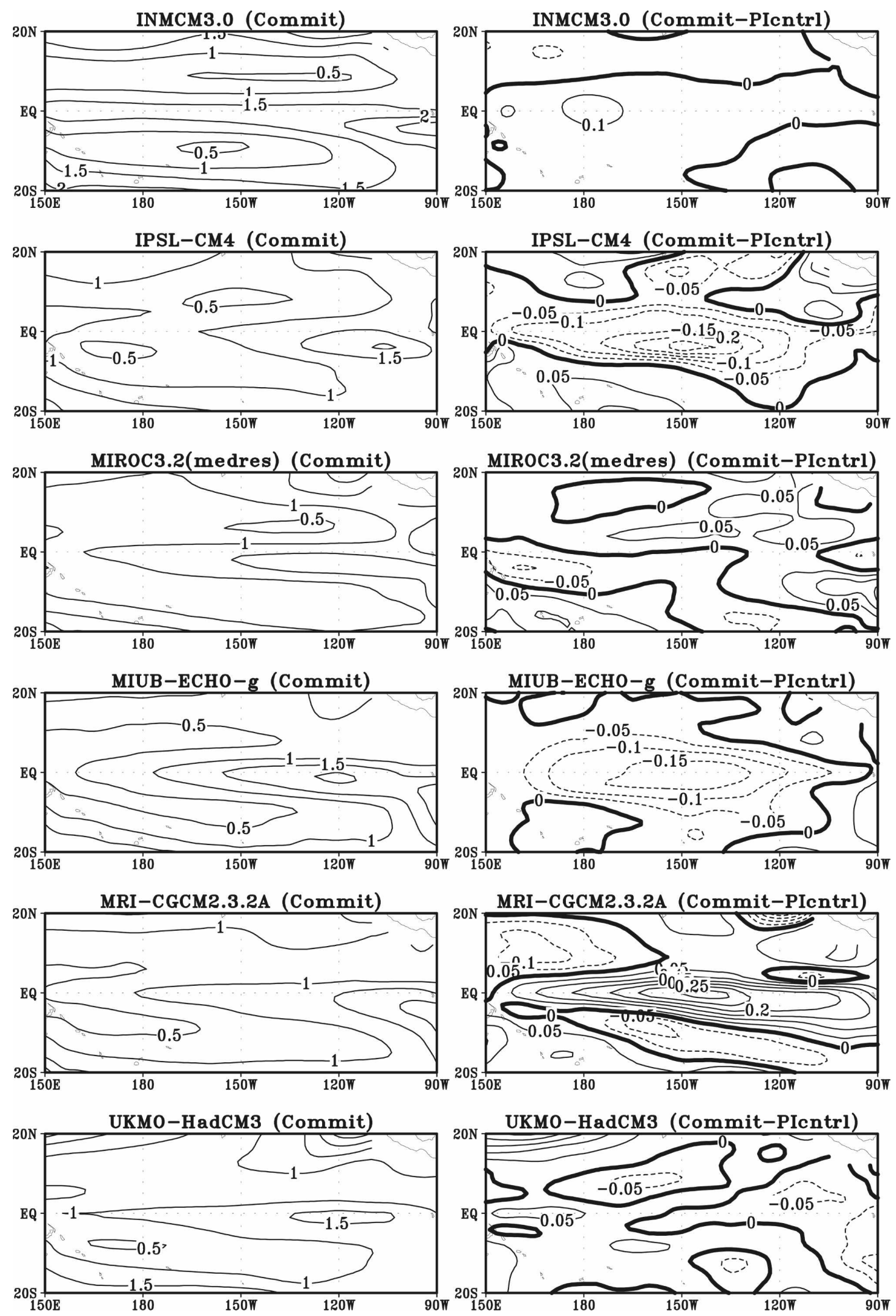

FIG. A2. (Continued) 
the multimodel results comparing the climate from year $2000 \mathrm{GHG}$ (+aerosol) forcing (Commit) with the preindustrial climate (PIcntrl). Both the equatorial zonal overturning circulation and the meridional overturning circulation weakened with increased GHG. The idea that the GHGs might play a role on the slowdown of the zonal and meridional overturning circulations received strong support from the multimodel ensemble means. This conclusion also matches the finding that the Walker circulation in the atmosphere has been weakening since the mid-nineteenth century owing to the anthropogenic forcing (Vecchi et al. 2006).

In the observed SST data, the positive anomalies during El Niño were located farther east in the 1950-99 composite than in the 1900-49 composite, whereas the negative anomalies during La Niña were shifted in the opposite direction. From the model data, the positive SST anomalies during El Niño also shifted eastward in the Commit runs relative to the PIcntrl runs, whereas the negative SST anomalies during La Niña were not shifted zonally. Hence, both model and observed SST results were consistent with increasing asymmetry between El Niño and La Niña as GHG increased. The increase in the asymmetry is associated with an increase in the nonlinearity of ENSO (Jin et al. 2003; An and Jin 2004), with the nonlinear dynamical heating (NDH) terms producing the asymmetry between El Niño and La Niña. A diagnostic analysis of the ocean surface temperature tendency equation revealed the vertical NDH term to be most dominant, with the positive vertical NDH anomalies in the equatorial Pacific enhanced substantially in the Commit runs during El Niño, caused by the increased vertical temperature gradient anomalies and the eastward shift of downwelling anomalies. Under increased GHG, the enhanced positive NDH anomalies during El Niño when time averaged over the whole record would change the SST mean state by an El Niño-like pattern, which could override other mechanisms trying to induce a La Niñalike change in the mean state (Cane et al. 1997).

For the simulated equatorial zonal circulation associated with ENSO, the zonal undercurrent anomalies during El Niño strengthened slightly and shifted eastward in the Commit runs relative to the PIcntrl runs, whereas the undercurrent anomalies during La Niña weakened and shifted slightly westward instead. For the simulated meridional overturning circulation in the Pacific, the interior path from the eastern subtropical Pacific to the central equatorial region was clearly seen during both El Niño and La Niña. With the NDH increasing nonlinearity and asymmetry between El Niño and La Niña in the enhanced GHG experiments, simulations with enhanced GHG showed that the asymme- try was enhanced in the anomalies of the SST, the zonal wind stress, the equatorial undercurrent, and the meridional overturning circulation.

Acknowledgments. We thank Dr. Aiming Wu for helpful discussions. We acknowledge the modeling groups for providing their data for analysis, the Program for Climate Model Diagnosis and Intercomparison (PCMDI) for collecting and archiving the model output, and the JSC/CLIVAR Working Group on Coupled Modelling (WGCM) for organizing the model data analysis activity. The multimodel data archive is supported by the Office of Science, U.S. Department of Energy. NOAA-ERSST-V2 data is provided by the NOAA/OAR/ESRL PSD, Boulder, Colorado, from their Web site at http://www.cdc.noaa.gov/. This work was supported by the Natural Sciences and Engineering Research Council of Canada.

\section{APPENDIX}

\section{SST Patterns}

Maps of SST mean and standard deviation are given for individual models in Figs. A1 and A2.

All 12 models exhibited positive patterns over the equatorial Pacific in the differences between Commit runs and PIcntrl runs (Fig. A1), despite the mean SST pattern being quite different for each model. The standard deviations for each model (Fig. A2) showed that, with increased GHG, the ENSO amplitude increased in two models (GFDL CM2.0 and MRI CGCM2.3.2a), but decreased in two models (IPSL CM4 and MIUB ECHO-G). For the other eight models, it is unclear whether the ENSO amplitudes have changed in the Commit runs compared to the PIcntrl runs.

\section{REFERENCES}

An, S.-I., 2004: Interdecadal changes in the El Niño-La Niña asymmetry. Geophys. Res. Lett., 31, L23210, doi:10.1029/ 2004GL021699.

- and B. Wang, 2000: Interdecadal change of the structure of the ENSO mode and its impact on the ENSO frequency. $J$. Climate, 13, 2044-2055.

, and F.-F. Jin, 2004: Nonlinearity and asymmetry of ENSO. J. Climate, 17, 2399-2412.

Anthes, R. A., R. W. Corell, G. Holland, J. W. Hurrell, M. C. MacCracken, and K. E. Trenberth, 2006: Hurricanes and global warming-Potential linkages and consequences. Bull. Amer. Meteor. Soc., 87, 623-628.

Barnett, T. P., D. W. Pierce, M. Latif, D. Dommenget, and R. Saravanan, 1999: Interdecadal interactions between the tropics and midlatitudes in the Pacific basin. Geophys. Res. Lett., 26, 615-618.

Betts, A. K., and W. Ridgway, 1989: Climatic equilibrium of the 
atmospheric convective boundary layer over a tropical ocean. J. Atmos. Sci., 46, 2621-2641.

Cane, M. A., A. C. Clement, A. Kaplan, Y. Kushnir, D. Pozdnyakov, R. Seager, S. E. Zebiak, and R. Murtugudde, 1997: Twentieth-century sea surface temperature trends. Science, 275, 957-960.

Capotondi, A., A. T. Wittenberg, and S. Masina, 2006: Spatial and temporal structure of tropical Pacific interannual variability in 20th century coupled simulations. Ocean Modell., 15, 274298.

Collins, M., and Coauthors, 2005: El Niño- or La Niña-like climate change? Climate Dyn., 24, 89-104, doi:10.1007/s00382-0040478-x.

Dai, A., 2006: Precipitation characteristics in eighteen coupled climate models. J. Climate, 19, 4605-4630.

Fedorov, A. V., and S. G. H. Philander, 2001: A stability analysis of tropical ocean-atmosphere interactions: Bridging measurements of and theory for El Niño. J. Climate, 14, 30863101.

Flügel, M., P. Chang, and C. Penland, 2004: The role of stochastic forcing in modulating ENSO predictability. J. Climate, 17, 3125-3140.

Gu, D., and S. G. H. Philander, 1997: Interdecadal climate fluctuations that depend on exchanges between the tropics and extratropics. Science, 275, 805-807.

Guilyardi, E., 2006: El Niño-mean state-seasonal cycle interactions in a multi-model ensemble. Climate Dyn., 26, 329-348, doi:10.1007/s00382-005-0084-6.

Held, I. M., and B. J. Soden, 2006: Robust responses of the hydrological cycle to global warming. J. Climate, 19, 5686-5699.

Houghton, J. T., Y. Ding, D. J. Griggs, M. Noguer, P. J. van der Linden, X. Dai, K. Maskell, and C. A. Johnson, Eds., 2001: Climate Change 2001: The Scientific Basis. Cambridge University Press, $881 \mathrm{pp}$.

Jin, F.-F., S.-I. An, A. Timmermann, and J. Zhao, 2003: Strong El Niño events and nonlinear dynamical heating. Geophys. Res. Lett., 30, 1120, doi:10.1029/2002GL016356.

Jones, P. D., and A. Moberg, 2003: Hemispheric and large-scale surface air temperature variations: An extensive revision and an update to 2001. J. Climate, 16, 206-223.

Kleeman, R., J. P. McCreary, and B. A. Klinger, 1999: A mechanism for generating ENSO decadal variability. Geophys. Res. Lett., 26, 1743-1746.

Knutson, T. R., and S. Manabe, 1998: Model assessment of decadal variability and trends in the tropical Pacific Ocean. $J$. Climate, 11, 2273-2296.

Liu, Z., 1994: A simple model of the mass exchange between the subtropical and tropical Ocean. J. Phys. Oceanogr., 24, 11531165.

McCreary, J. P., and P. Lu, 1994: Interaction between the sub- tropical and equatorial ocean circulations: The subtropical cell. J. Phys. Oceanogr., 24, 466-497.

McPhaden, M. J., and D. Zhang, 2002: Slowdown of the meridional overturning circulation in the upper Pacific Ocean. $\mathrm{Na}$ ture, 415, 606-608.

$\longrightarrow$, and - 2004: Pacific Ocean circulation rebounds. Geophys. Res. Lett., 31, L18301, doi:10.1029/2004GL020727.

Meehl, G. A., and W. M. Washington, 1996: El Niño-like climate change in a model with increased atmospheric $\mathrm{CO}_{2}$ concentrations. Nature, 382, 56-60.

Meehl, G. A., H. Teng, and G. W. Branstator, 2006: Future changes of El Niño in two global coupled climate models. Climate Dyn., 26, 549-566.

Merryfield, W. J., 2006: Changes to ENSO under $\mathrm{CO}_{2}$ doubling in a multi-model ensemble. J. Climate, 19, 4009-4027.

- and G. J. Boer, 2005: Variability of upper Pacific Ocean overturning in a coupled climate model. J. Climate, 18, 666683.

Rodgers, K. B., P. Friederichs, and M. Latif, 2004: Tropical Pacific decadal variability and its relation to decadal modulations of ENSO. J. Climate, 17, 3761-3774.

Smith, T. M., and R. W. Reynolds, 2004: Improved extended reconstruction of SST (1854-1997). J. Climate, 17, 2466-2477.

Thompson, C. J., and D. S. Battisti, 2001: A linear stochastic dynamical model of ENSO. Part II: Analysis. J. Climate, 14, 445-466.

Van Oldenborgh, G. J., S. Y. Philip, and M. Collins, 2005: El Niño in a changing climate: A multi-model study. Ocean Sci., 2, 267-298.

Vecchi, G. A., and B. J. Soden, 2007: Global warming and the weakening of the tropical circulation. J. Climate, 20, 43164340 .

-, A. T. Wittenberg, I. M. Held, A. Leetmaa, and M. J. Harrison, 2006: Weakening of tropical Pacific atmospheric circulation due to anthropogenic forcing. Nature, 44, 73-76.

Von Storch, H., and F. W. Zwiers, 1999: Statistical Analysis in Climate Research. Cambridge University Press, 484 pp.

Wu, A., and W. W. Hsieh, 2003: Nonlinear interdecadal changes of the El Niño-Southern Oscillation. Climate Dyn., 21, 719730.

Ye, Z., and W. W. Hsieh, 2006: The influence of climate regime shift on ENSO. Climate Dyn., 26, 823-833, doi:10.1007/ s00382-005-0105-5.

Zhang, D., and M. J. McPhaden, 2006: Decadal variability of the shallow Pacific meridional overturning circulation: Relation to tropical sea surface temperatures in observations and climate change models. Ocean Modell., 15, 250-273, doi:10.1016/j.ocemod.2005.12.005.f

Zhang, G. J., and H. Wang, 2006: Toward mitigating the double ITCZ problem in NCAR CCSM3. Geophys. Res. Lett., 33, L06709, doi:10.1029/2005GL025229. 